\title{
Fluid temperature predictions of geothermal borefields using load estimations via state observers
}

\author{
Iago Cupeiro Figueroa ${ }^{\mathrm{a}, \mathrm{b}}$, Massimo Cimmino $^{\mathrm{c}}$, Ján Drgoňa $^{\mathrm{d}}$, Lieve Helsen ${ }^{\mathrm{a}, \mathrm{b}}$ \\ ${ }^{a}$ University of Leuven (KU Leuven), Department of Mechanical Engineering, 3001 Leuven, \\ Belgium \\ ${ }^{b}$ EnergyVille, Thor Park 8310, 3600 Genk, Belgium \\ ${ }^{c}$ École Polytechnique de Montréal, Département de génie mécanique, Montréal, Québec, \\ H3C3A7, Canada \\ ${ }^{d}$ Pacific Northwest National Laboratory, Richland, WA, United States
}

\begin{abstract}
Fluid temperature predictions of geothermal borefields usually involve temporal superposition of its characteristic g-function, using load aggregation schemes to reduce computational times. Assuming that the ground has linear properties, it can be modeled as a linear state space system where the states are the aggregated loads. However, the application and accuracy of these models is compromised when the borefield is already operating and its load history is not registered or there are gaps in the data. This paper assesses the performance of state observers to estimate the borefield load history to obtain accurate fluid predictions. Results show that both Time-Varying Kalman Filter (TVKF) and Moving Horizon Estimator (MHE) provide predictions with average and maximum errors below $0.1{ }^{\circ} \mathrm{C}$ and $1{ }^{\circ} \mathrm{C}$ respectively. MHE outperforms TVKF in terms of n-step ahead output predictions and load history profile estimates at the expense of about 5 times more computational time.
\end{abstract}

Keywords: Geothermal modeling, Fluid temperature prediction, Load estimation, State observers, Kalman Filter, Moving Horizon Estimation,

\section{Nomenclature}

\footnotetext{
* Corresponding author

Email address: iago.cupeirofigueroa@kuleuven.be (Iago Cupeiro Figueroa)
} 


\begin{tabular}{|c|c|c|c|c|}
\hline & $\alpha$ & Thermal diffusivity $\left(\mathrm{m} \mathrm{s}^{-2}\right)$ & $n$ & Number of instances (-) \\
\hline & \multirow[t]{2}{*}{$\Delta t$} & Load aggregation resolutioß & $N$ & Number of time-steps (-) \\
\hline & & $(\mathrm{s}))$ & $O$ & Observer \\
\hline \multirow[t]{5}{*}{5} & $\Gamma$ & Arrival cost & $p$ & Model parameter $\left(\mathrm{kg} \mathrm{s}^{-1}\right)$ \\
\hline & $\kappa$ & Weighting factor (-) & $P$ & Error covariance matrix \\
\hline & $\rho$ & Density $\left(\mathrm{kg} \mathrm{m}^{-3}\right)$ & $\dot{q}$ & Thermal power per unit length \\
\hline & $\tau$ & Moving-backwards time (s) & & $\left(\mathrm{W} \mathrm{m}^{-1}\right)$ \\
\hline & $A$ & State matrix & $\dot{Q}$ & Thermal power $(\mathrm{W})$ \\
\hline \multirow[t]{5}{*}{10} & $A A D$ & Average absolute temperature & $Q$ & Thermal energy $(\mathrm{J})$ \\
\hline & & difference $(\mathrm{K})$ or $\left({ }^{\circ} \mathrm{C}\right)$ & $r$ & Radius (m) \\
\hline & $A A O E$ & $\begin{array}{l}\text { Average absolute output error } \\
(\mathrm{K}) \text { or }\left({ }^{\circ} \mathrm{C}\right)\end{array}$ & $R$ & Thermal resistance $\left(\mathrm{m} \mathrm{K} \mathrm{W}^{-1}\right)$ \\
\hline & & 40 & & or measurement noise matrix \\
\hline & $B$ & $\ln p$ & $S$ & Process noise matrix \\
\hline \multirow[t]{4}{*}{15} & $C$ & $\begin{array}{l}\text { Output matrix or Thermal ca- } \\
\text { pacity }(\mathrm{J} / \mathrm{K})\end{array}$ & $t$ & Time (s)) \\
\hline & $c_{p}$ & Specific heat capacity $\left(\mathrm{J} \mathrm{kg}^{-1}\right.$ & $T$ & Temperature $(\mathrm{K})$ or $\left({ }^{\circ} \mathrm{C}\right)$ \\
\hline & & $\left.\mathrm{K}^{-1}\right)$ & $u$ & Model input (W) \\
\hline & $d$ & Buried depth $(\mathrm{m})$ or model dis ${ }^{45}$ & $v$ & Model measurement noise \\
\hline \multirow[t]{5}{*}{0} & & turbance & $V$ & Volume $\left(\mathrm{m}^{3}\right)$ \\
\hline & $e$ & Thickness (m) & $w$ & Model process noise \\
\hline & $g$ & g-Function (-) & $\hat{x}$ & Estimated state $(\mathrm{W}),(\mathrm{K})$ or \\
\hline & $H$ & Borehole length (m) & & $\left({ }^{\circ} \mathrm{C}\right)$ \\
\hline & $I$ & Identity matrix (-) & $x$ & Model state $(\mathrm{W}),(\mathrm{K})$ or $\left({ }^{\circ} \mathrm{C}\right)$, \\
\hline \multirow[t]{4}{*}{25} & $k$ & Thermal conductivity $\left(\mathrm{W} \mathrm{m}^{-1}\right.$ & & or shanking space $(\mathrm{m})$ \\
\hline & & $\left.\mathrm{K}^{-1}\right)$ & $y$ & Model output $(\mathrm{K})$ or $\left({ }^{\circ} \mathrm{C}\right)$ \\
\hline & $L$ & Kalman gain & $z$ & Axial direction \\
\hline & $\dot{m}$ & Mass flow rate $\left(\mathrm{kg} \mathrm{s}^{-1}\right)$ & Su & \\
\hline
\end{tabular}




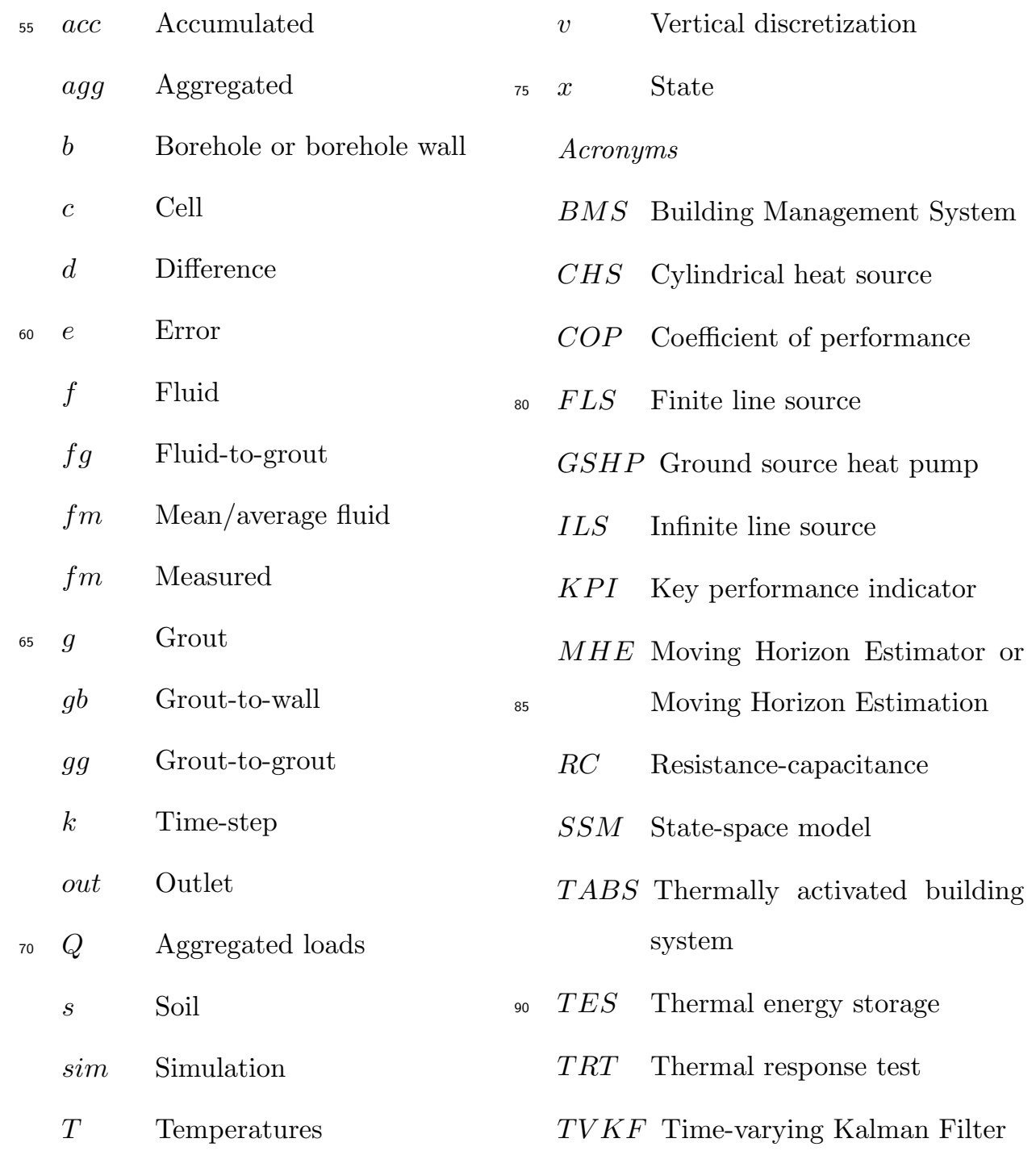

\section{Introduction}

Geothermal borefields are composed of multiple drillings of vertical boreholes to extract/inject heat from/into the ground. Typically, each borehole consists of one or two U-shaped pipes through which water or an anti-freeze mixture is circulated to realize the targeted heat transfer. Borefields are coupled with ground source heat pump (GSHP) and passive cooling heat exchanger systems, or used 
as thermal energy storage (TES) systems to provide efficient heating and cooling for buildings and districts. The efficiency of these systems is dependent on the fluid temperature that leaves the borefield. Therefore, knowing the borefield leaving fluid temperature is key both for optimal design and optimal control of the geothermal system. To this end, detailed borefield modeling is used to ultimately predict the fluid temperatures that leave the geothermal borefield. A common approach is to separately treat the modeling of the borehole and the ground and couple the two models at the borehole wall.

The relation between the borehole wall temperature and the average fluid temperature within the borehole is given by the effective borehole thermal resistance $R_{b}^{*}=\frac{T_{f m}-T_{b}}{\dot{q}_{b}}$, where $T_{f m}$ is the average fluid temperature, $T_{b}$ is the borehole wall temperature and $\dot{q}_{b}$ is the heat transfer rate (from the borehole to the ground) per unit length $(\mathrm{W} / \mathrm{m})$ [1]. Both analytical (Multipole, Claesson and Hellström [2]) and numerical methods (Finite element method, Lamarche et al. 3]) can be used to calculate this resistance. Resistance networks can be considered to add more level of detail and evaluate the temperatures in the different legs of the U-tubes. However, these approaches do not account for the transient heat transfer in the grout or the movement of the fluid flow through the U-tube legs. The borehole capacity can have a substantial influence as demonstrated by Shirazi and Bernier [4] and it can be taken into account by adding thermal capacitances to the resistance network [5, 6]. To account for the heat transfer effects of the fluid flow moving through the piping, the borehole can be vertically discretized [7, 8]. Each discretization comprises a thermal resistance-capacitance (RC) network and they are coupled by advection heat transfer equations. Consequently, the vertical variation of the fluid temperature is taken into account, improving the accuracy of the borehole outlet fluid temperature $T_{\text {out }}$.

To model the ground, the pioneer work of Eskilson and Claesson [9] introduced the so-called 'g-functions', which are dimensionless thermal response factors of the ground for a given borefield geometry. In his thesis, Eskilson computed the g-functions numerically considering the ground as a homogeneous 
inlet and borehole wall temperature for all boreholes. Following the work of Eskilson, several authors tried to analytically determine the g-function of the borefield using the Infinite Line Source (ILS, Ingersoll and Plass [10]), Cylindrical Line Source (CLS, Carslaw and Jaeger [1]) and Finite Line Source (FLS, Claesson and Eskilson [12]) approaches. These approaches determine the temperature profile in the ground for an individual borehole when a constant heat load is applied. As the ground is assummed to be homogeneous, i.e. the ground properties are linear, spatial superposition can be applied to obtain the thermal response of a borefield. Then, temporal superposition can be applied to obtain the ground response under a variable heat load. However, the number of superposition calculations is proportional to the square of the number of time steps, therefore escalating the problem complexity as it advances in time. Since the loads far in time have less impact than the inmediate applied loads, load aggregation schemes are proposed to reduce the computational burden. A comprehensive review of load aggregation schemes can be found in Mitchell and Spitler [13. Some examples include the ones proposed by Bernier et al. [14] and Claesson and Javed [15].

More recently, interest in simpler models oriented towards model-based optimal control has increased. Model-based optimal control aims to minimize an objective function over a finite period of time, relying on the predictions made by the model. A common strategy for these models is to model the heat diffusion in the ground as a 1D RC network, considering a constant undisturbed ground temperature in the far field [16], incorporating the geothermal gradient [17] or even taking into account the effects of the fluid mass flow rate [18]. ground nodes. The ground long-term effects, such as thermal interference between multiple boreholes or axial heat transfer are often not accounted for, however state updates can be introduced to incorporate these [19]. Other authors prefer data-driven modeling approaches using data from more accurate 160 
ground model formulation for optimal control based on the thermal response of the borefield.

Either for simulation or optimization, the accuracy of these models to predict the fluid temperature is compromised if the borefield load history is not known. 165 A priori, this lack of information may not be a problem for the assessment and sizing of new and isolated installations, where there is no previous load history. However, in model-based optimal control applications this can lead to issues in the operation phase. The prediction of the fluid temperature significantly influences the efficiency of the GSHP system and its ability to supply passive cooling. Thus, the control decisions taken by the optimal controller are affected by this prediction. An incorrect prediction of the borefield fluid temperature may lead to sub-optimal and detrimental control actions. It is not rare to encounter operating installations which are either not being monitored or lack high-quality data. Moreover, the measurement instruments (e.g., calorimeters) normally measure fluid heat flow rate $\dot{Q}_{f}$, which does not necessarily coincide with the ground heat flow rate $\dot{Q}_{b}$ as depicted in Figure 1 Finally, there is always a degree of uncertainty related not only to the measurement data but also to model parameters that can be re-estimated after a period of operation [24] or to the presence of neighbouring boreholes that can interfere with the ground load history [25].

Extending the methodology developed by Cupeiro Figueroa et al. [19, 26], this paper proposes a method to estimate the load history of non-monitored operational borefield installations using state observers to obtain accurate borefield fluid predictions. State observers are feedback systems that provide an estimate of the internal states of a given model from measurements of the inputs and outputs of the real system to minimize the next-step output error. They are widely used in model-based optimal control applications to minimize the error on the current state of the system model and improve the accuracy of the predictions. The performance of these state observers to estimate the borefield load history and predicting the fluid temperature is assessed in both the short and long-term. Section 2 elaborates on the methodology used. Sec- 


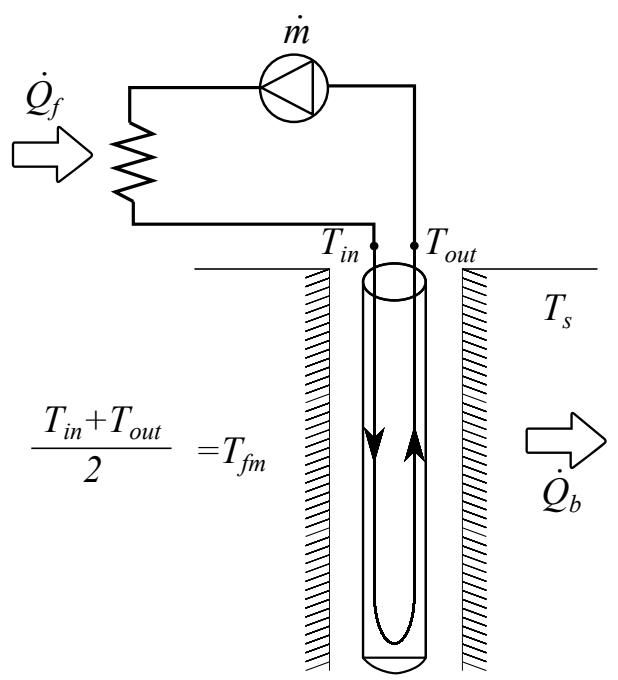

Figure 1: Distinction between the fluid heat flow $\dot{Q}_{f}$ and the borefield heat flow $\dot{Q}_{b}$.

tion 3 describes the case study building from which the data is extracted and further details on the experiment set-up, such as the initialization of the states $x_{0}$. The resulting vectors of aggregated loads and the fluid temperature predictions from the simulations are discussed in Section 4 . Finally, conclusions are drawn in Section 5 ,

\section{Methodology}

Figure 2 shows a schematic of the methodology used in this paper. A generic borefield model is calibrated using the technical datasheets and information from a real installation of an office building located in Dilbeek, Brussels. The model can be represented as a state-space model (SSM) with a parameterized $A$ matrix. The model input $u$ is the heat flow to the fluid $\dot{Q}_{f}$ and the output $y$ is the mean fluid temperature $T_{f m}$. The states $x$ of the model are the fluid and grout temperatures and the vector of aggregated loads $\dot{Q}_{a g g}$. The parameter $p$ is the mass flow rate through the borefield $\dot{m}$. A further description of the model can be found in Section 2.1. Using a frame of historical data (fluid heat and mass flow rates) stored within the Building Management System (BMS) 


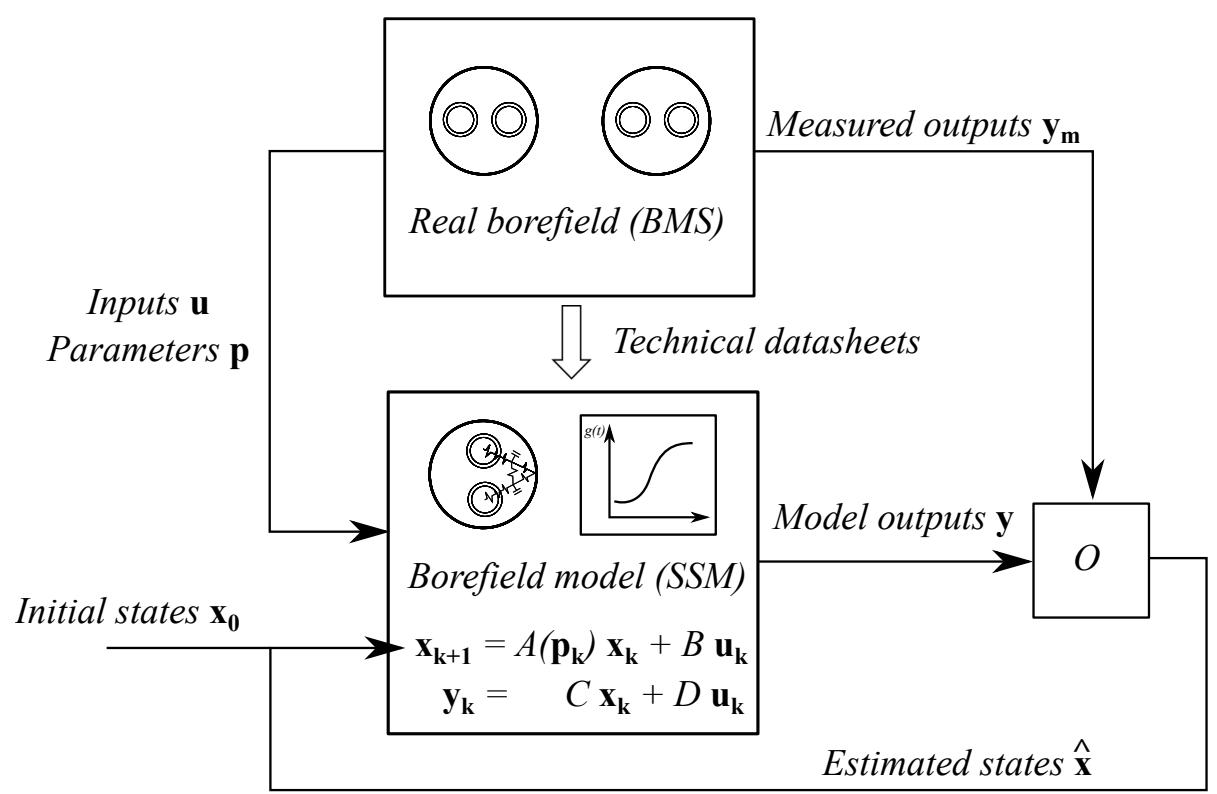

Figure 2: Schematic view of the methodology. The model is initiated with a set of states $x_{0}$. At each time-step $k$ the borefield model is fed with the required inputs $\mathbf{u}$ and parameters $\mathbf{p}$ extracted from the BMS system, and the states from the previous step. The resulting outputs $\mathbf{y}$ and states $\mathbf{x}$ receive feedback information from the output measurements $\mathbf{y}_{\mathbf{m}}$ to compute a new state vector of estimates $\hat{\mathbf{x}}$.

the model simulation is coupled with the state observer $O$ that uses the BMS measurements $y_{m}$ to estimate the new vector of states $\hat{x}$ for the next simulation time-step. Three cases are considered: (i) No state observer $O$ is applied, i.e. the simulation is run in open-loop, (ii) the observer $O$ is a Time-varying Kalman Filter (TVKF) and (iii) the observer $O$ is a Moving Horizon Estimator (MHE). More details about the algorithms of the considered estimators can be found in Section 2.2 .

\subsection{Borefield model}

The borefield model is based on the one developed by Laferriere et al. [27. It uses separate borehole and ground models which are connected through the wall temperature of the borehole. All the $n_{b}$ boreholes in the field are lumped into one single borehole. The borehole model is discretized in a number of 
segments $n_{v}$ along the axial direction. For each vertical discretization, radial heat transfer is considered through the resistance-capacitance networks developed by Bauer et al. [5] and shown in Figure 3. We refer to their work for further details about the calculation of the fluid-to-grout $R_{f g}$, grout-to-grout $R_{g g 1}, R_{g g 2}$ and grout-to-wall $R_{g b}$ resistances and the grout capacitances $C_{g}$. To 225 add the fluid transport component, each discretization $i$ is connected to advection heat transfer equations. Applying energy balances on the nodes of the resistance-capacitance network yields:

for the fluid nodes:

$$
\begin{aligned}
& \rho_{f} V_{f 1, i} c_{p, f} \frac{d T_{f 1, i}}{d t}=\frac{T_{g 1, i}-T_{f 1, i}}{R_{f g}}-\dot{m} c_{p}\left(T_{f 1, i}-T_{f 1, i-1}\right) \\
& \rho_{f} V_{f 2, i} c_{p, f} \frac{d T_{f 2, i}}{d t}=\frac{T_{g 2, i}-T_{f 2, i}}{R_{f g}}-\dot{m} c_{p}\left(T_{f 2, i}-T_{f 2, i+1}\right)
\end{aligned}
$$

for the grout nodes:

$$
\begin{aligned}
C_{g} \frac{d T_{g 1, i}}{d t} & =\frac{T_{f 1, i}-T_{g 1, i}}{R_{f g}}+\frac{T_{g 2, i}-T_{g 1, i}}{R_{g g 1}}-\frac{T_{g 1, i}-T_{b, i}}{R_{g b}} \\
C_{g} \frac{d T_{g 2, i}}{d t} & =\frac{T_{f 2, i}-T_{g 2, i}}{R_{f g}}+\frac{T_{g 1, i}-T_{g 2, i}}{R_{g g 1}}-\frac{T_{g 2, i}-T_{b, i}}{R_{g b}}
\end{aligned}
$$

and for the wall node:

$$
\dot{Q}_{b, i}=\frac{T_{g 1, i}-T_{b, i}}{R_{g b}}+\frac{T_{g 2, i}-T_{b, i}}{R_{g b}}
$$

Analogously, for a double U-tube borehole:

for the fluid nodes: 

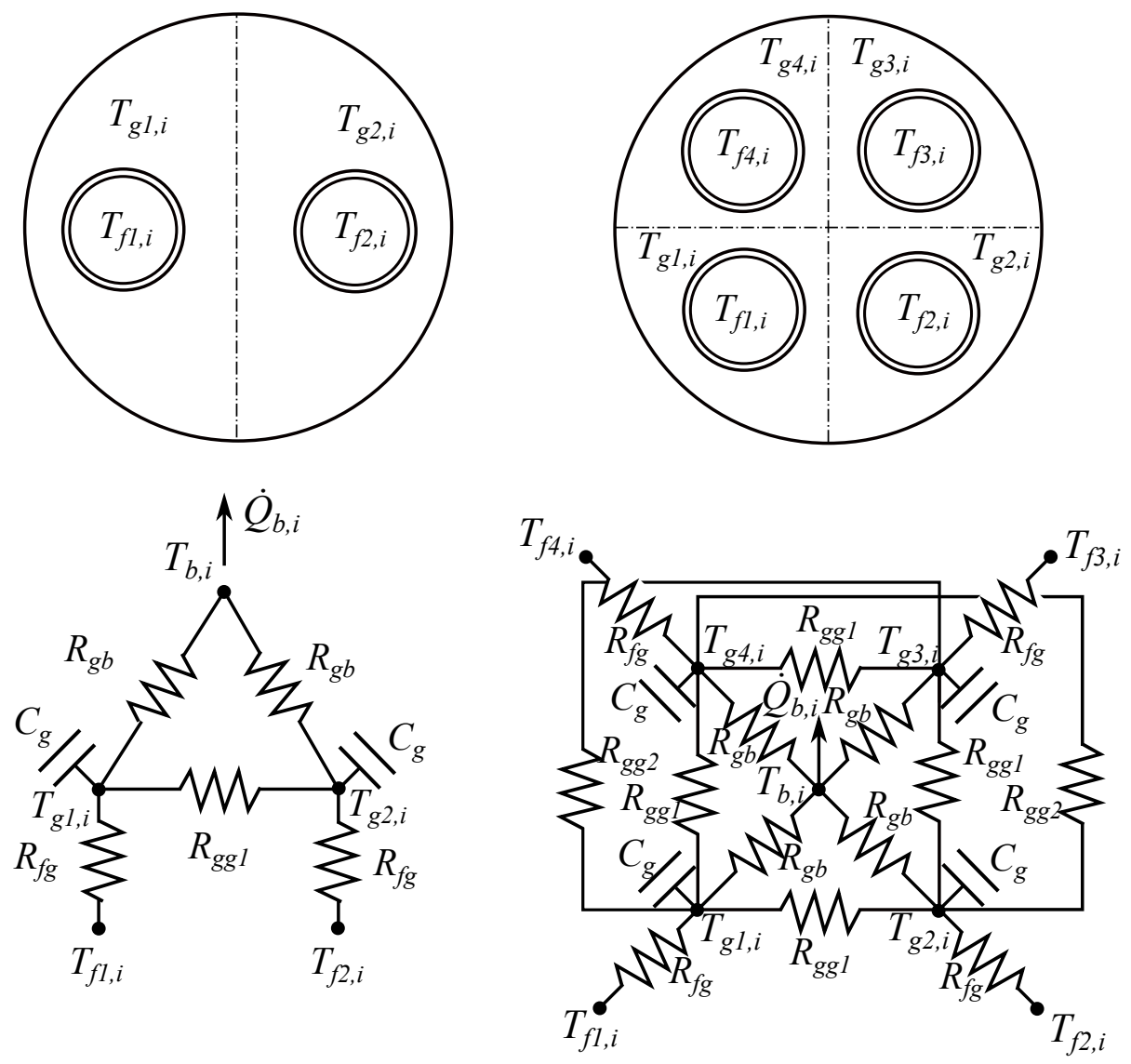

Figure 3: Radial cross-sections, resistance-capacitance networks and nomenclature used in the borehole model for the i-th discretization: $T_{f}$ fluid temperatures, $T_{g}$ grout temperatures, $T_{b}$ borehole wall temperatures, $C_{g}$ grout thermal capacities, $R$ thermal resistances, $\dot{Q}_{b}$ heat flow injected/extracted into/from the ground. The subscripts 1 and 3 refer to the downward-flow legs, while the subscripts 2 and 4 refer to the upward-flow legs. Adaptation from Bauer et al. [5]. 


$$
\begin{aligned}
& \rho_{f} V_{f 1, i} c_{p, f} \frac{d T_{f 1, i}}{d t}=\frac{T_{g 1, i}-T_{f 1, i}}{R_{f g}}-\dot{m} c_{p}\left(T_{f 1, i}-T_{f 1, i-1}\right) \\
& \rho_{f} V_{f 2, i} c_{p, f} \frac{d T_{f 2, i}}{d t}=\frac{T_{g 2, i}-T_{f 2, i}}{R_{f g}}-\dot{m} c_{p}\left(T_{f 2, i}-T_{f 2, i+1}\right) \\
& \rho_{f} V_{f 3, i} c_{p, f} \frac{d T_{f 3, i}}{d t}=\frac{T_{g 3, i}-T_{f 3, i}}{R_{f g}}-\dot{m} c_{p}\left(T_{f 3, i}-T_{f 3, i-1}\right) \\
& \rho_{f} V_{f 4, i} c_{p, f} \frac{d T_{f 4, i}}{d t}=\frac{T_{g 4, i}-T_{f 4, i}}{R_{f g}}-\dot{m} c_{p}\left(T_{f 4, i}-T_{f 4, i+1}\right)
\end{aligned}
$$

for the grout nodes:

$$
\begin{aligned}
& C_{g} \frac{d T_{g 1, i}}{d t}=\frac{T_{f 1, i}-T_{g 1, i}}{R_{f g}}+\frac{T_{g 2, i}-T_{g 1, i}}{R_{g g 1}}+\frac{T_{g 3, i}-T_{g 1, i}}{R_{g g 2}}+\frac{T_{g 4, i}-T_{g 1, i}}{R_{g g 1}}-\frac{T_{g 1, i}-T_{b, i}}{R_{g b}} \\
& C_{g} \frac{d T_{g 2, i}}{d t}=\frac{T_{f 2, i}-T_{g 2, i}}{R_{f g}}+\frac{T_{g 1, i}-T_{g 2, i}}{R_{g g 1}}+\frac{T_{g 4, i}-T_{g 2, i}}{R_{g g 2}}+\frac{T_{g 3, i}-T_{g 2, i}}{R_{g g 1}}-\frac{T_{g 2, i}-T_{b, i}}{R_{g b}} \\
& C_{g} \frac{d T_{g 3, i}}{d t}=\frac{T_{f 3, i}-T_{g 3, i}}{R_{f g}}+\frac{T_{g 2, i}-T_{g 3, i}}{R_{g g 1}}+\frac{T_{g 1, i}-T_{g 3, i}}{R_{g g 2}}+\frac{T_{g 4, i}-T_{g 3, i}}{R_{g g 1}}-\frac{T_{g 3, i}-T_{b, i}}{R_{g b}} \\
& C_{g} \frac{d T_{g 4, i}}{d t}=\frac{T_{f 4, i}-T_{g 4, i}}{R_{f g}}+\frac{T_{g 1, i}-T_{g 4, i}}{R_{g g 1}}+\frac{T_{g 2, i}-T_{g 4, i}}{R_{g g 2}}+\frac{T_{g 3, i}-T_{g 4, i}}{R_{g g 1}}-\frac{T_{g 4, i}-T_{b, i}}{R_{g b}}
\end{aligned}
$$

and for the wall node:

$$
\dot{Q}_{b, i}=\frac{T_{g 1, i}-T_{b, i}}{R_{g b}}+\frac{T_{g 2, i}-T_{b, i}}{R_{g b}}+\frac{T_{g 3, i}-T_{b, i}}{R_{g b}}+\frac{T_{g 4, i}-T_{b, i}}{R_{g b}}
$$

The mean fluid temperature $T_{f m}$ is given by the average of the inlet and outlet of the borehole:

$$
T_{f m}= \begin{cases}\frac{1}{2}\left(T_{f 1,0}+T_{f 2,1}\right) & \text { single U-tube } \\ \frac{1}{4}\left(T_{f 1,0}+T_{f 2,1}+T_{f 3,0}+T_{f 4,1}\right) & \text { double U-tube }\end{cases}
$$


and the total borefield load equals the sum of all the segment loads, multiplied by the number of boreholes $n_{b}$ :

$$
\dot{Q}_{b}=n_{b} \sum_{i=1}^{n_{v}} \dot{Q}_{b, i}
$$

Moreover, the following boundary and initial conditions are imposed:

$$
\begin{aligned}
\dot{Q}_{f} & = \begin{cases}\dot{m} c_{p}\left(T_{f 1,0}-T_{f 2,1}\right) & \text { single U-tube } \\
\frac{\dot{m} c_{p}}{2}\left(T_{f 1,0}-T_{f 2,1}+T_{f 3,0}-T_{f 4,1}\right) & \text { double U-tube }\end{cases} \\
T_{s, i} & =T_{\{f 1, f 2, f 3, f 4, g 1, g 2, g 3, g 4\}, i}(t=0) \\
T_{f 2, n_{v}+1} & =T_{f 1, n_{v}} \\
T_{f 4, n_{v}+1} & =T_{f 3, n_{v}}
\end{aligned}
$$

where $T_{s, i}$ is the undisturbed ground temperature in the far field at the discretization $i$, thus accounting for the geothermal gradient. The borehole model dynamic equations (Equations 1, 2, 3, and 5b can be re-arranged and represented as a state-space model as shown in Equation 6, where $A_{T}, B_{T}$ and $C_{T}$ are the matrices of the linear state-space model. $A_{T}$ represents a time linear transfer map of the discretized fluid and grout temperatures $\left(T_{f 1,1}, T_{f 2,1}\right.$, $\left.{ }_{240} T_{g 1,1}, T_{g 2,1}, \ldots\right), B_{T}$ is the heat gain matrix from the fluid heat flow $\left(\dot{Q}_{f}\right)$, while $C_{T}$ represents the mapping of the discretized fluid and grout temperatures to the mean fluid temperature $\left(T_{f m}\right)$. The states of the model are the fluid and grout temperatures for each discretization, represented by the vector $1 \mathbf{T}$ in Equation 6c. Note that the borehole model $A_{T}(\mathbf{p})$ matrix is dependant on the mass flow rate circulating through the borefield due to (i) the fluid transport component and (ii) the variability of $R_{f g}$ with the convective heat transfer coeffficient. As a result, the $A_{T}(\mathbf{p})$ matrix is parameterized, with the parameter $\mathbf{p}$ representing the mass flow rate $\dot{m}$. The size of the state-space

\footnotetext{
${ }^{1}$ We represent the vectors with upright boldface notation while the matrices use non-bold italic notation.
} 
model depends on the number of considered vertical discretizations $n_{v}$ and the pipe configuration of the borehole (single U-tube or double U-tube).

$$
\begin{aligned}
\frac{\partial \mathbf{T}}{\partial t} & =A_{T}(\mathbf{p}) \quad \mathbf{T}+B_{T} \quad \dot{\mathbf{Q}}_{\mathbf{f}} \\
\mathbf{T}_{\mathbf{f m}} & =C_{T} \mathbf{T} \\
\mathbf{T} & =\left[T_{f 1,1}, T_{f 2,1},\left(T_{f 3,1}, T_{f 4,1}\right), T_{g 1,1}, T_{g 2,1},\left(T_{g 3,1}, T_{g 4,1}\right), \ldots\right]^{T} \\
\dot{\mathbf{Q}}_{\mathbf{f}} & =\left[\dot{Q}_{f}\right]^{T} \\
\mathbf{T}_{\mathbf{f m}} & =\left[T_{f m}\right]^{T}
\end{aligned}
$$

The ground model computes the effective borehole wall temperature in the borefield, $T_{b}$, from the temporal superposition of the $g$-function, $g(t)[9,28,29$ ] as presented by Equation 7 .

$$
T_{b}(t)=\int_{0}^{t} \frac{d g}{d \tau} \cdot \frac{\dot{Q}_{b}(t-\tau)}{2 \pi k_{s} H n_{b}} d \tau
$$

To reduce the computational time, the history of borefield loads, $\dot{Q}_{b}$, is aggregated using a continuous load aggregation scheme, in line with the continuous state-space model in Equation 6 Several discrete load aggregation methods are available in the literature with varying levels of performance and computational speed, as analysed by Mitchell and Spitler [13. Here, a continuous scheme is constructed in analogy with convection phenomena, where historical borefield loads are akin to loads advected through time, that is :

$$
\begin{aligned}
\frac{\partial \dot{Q}_{a g g}}{\partial t} & =-\frac{\partial \dot{Q}_{a g g}}{\partial \tau} \\
\dot{Q}_{a g g}(t=0, \tau) & =0 \\
\dot{Q}_{a g g}(t, \tau=0) & =\dot{Q}_{b}(t)
\end{aligned}
$$

where $\dot{Q}_{a g g}$ is the load history of the borefield and $\tau$ is the time moving backwards through the load history, such that the exact solution to Equation 8 yields $\dot{Q}_{a g g}(t, \tau)=\dot{Q}_{b}(t-\tau)$. A state-space formulation is obtained 
by discretizing the load history into load aggregation cells and expressing the $\tau$ [30] is adopted :

$$
\begin{aligned}
\dot{Q}_{a g g, k} & =\frac{\dot{Q}_{a g g, k-1 / 2}-\dot{Q}_{a g g, k+1 / 2}}{\Delta \tau_{k}} \\
\dot{Q}_{a g g, k-1 / 2} & =\frac{\dot{Q}_{a g g, k-1}+\dot{Q}_{a g g, k}}{2}-\frac{\left(\tau_{k}-\tau_{k-1}\right)^{2}}{8 \Delta \tau_{k-1}}\left(\frac{\dot{Q}_{a g g, k}-\dot{Q}_{a g g, k-1}}{\tau_{k}-\tau_{k-1}}-\frac{\dot{Q}_{a g g, k-1}-\dot{Q}_{a g g, k-2}}{\tau_{k-1}-\tau_{k-2}}\right)
\end{aligned}
$$

$$
\dot{Q}_{a g g, k+1 / 2}=\frac{\dot{Q}_{a g g, k}+\dot{Q}_{a g g, k+1}}{2}-\frac{\left(\tau_{k+1}-\tau_{k}\right)^{2}}{8 \Delta \tau_{k}}\left(\frac{\dot{Q}_{a g g, k+1}-\dot{Q}_{a g g, k}}{\tau_{k+1}-\tau_{k}}-\frac{\dot{Q}_{a g g, k}-\dot{Q}_{a g g, k-1}}{\tau_{k}-\tau_{k-1}}\right)
$$

$$
\dot{Q}_{a g g, 1 / 2}=\dot{Q}_{b}
$$

where $\dot{Q}_{a g g, k}$ is the aggregated load in the $k$-th aggregation cell, and $\dot{Q}_{a g g, k-1 / 2}$ and $\dot{Q}_{a g g, k+1 / 2}$ are the interpolated loads at the left and right faces of the $k$-th load aggregation cell, respectively.

The load history is discretized into geometrically expanding cells [15] :

$$
\begin{aligned}
\Delta \tau_{k} & =\Delta t_{0} \cdot 2^{\left\lfloor\frac{k-1}{5}\right\rfloor} \\
\tau_{k} & =\sum_{p=1}^{k} \Delta \tau_{p}
\end{aligned}
$$

where $\Delta t_{0}$ is the width of the first aggregation cell. The number of aggregation cells, $n_{c}$, is selected such that the time of the last cell, $\tau_{n_{c}}$, is larger than the maximum simulation time.

${ }_{275} \quad$ Each aggregated load $\dot{Q}_{a g g, k}$ proportionally contributes to the borehole wall temperature increase/decrease by a weighting factor $\kappa_{k}$ given by the discrete form of Equation 7 


$$
\begin{aligned}
T_{b} & =\sum_{k=1}^{n_{c}} \dot{Q}_{a g g, k} \kappa_{k} \\
\kappa_{k} & =\frac{g\left(\tau_{k}\right)-g\left(\tau_{k-1}\right)}{2 \pi k_{s} H n_{b}}
\end{aligned}
$$

The accumulated load in the ground is given by:

$$
Q_{a c c}=\sum_{k=1}^{n_{c}} \dot{Q}_{a g g, k} \Delta \tau_{k}
$$

Re-arranging equations 9 and 11 results in the linear state-space model represented in Equation 13, where the states of the ground model are the vector of aggregated loads. The size of the state-space model depends on the number of aggregation cells.

$$
\begin{aligned}
\frac{\partial \dot{\mathbf{Q}}_{\mathbf{a g g}}}{\partial t} & =A_{Q} \quad \dot{\mathbf{Q}}_{\mathbf{a g g}}+B_{Q} \quad \dot{\mathbf{Q}}_{\mathbf{b}} \\
\mathbf{T}_{\mathbf{b}} & =C_{Q} \quad \dot{\mathbf{Q}}_{\mathbf{a g g}} \\
\dot{\mathbf{Q}}_{\mathbf{a g g}} & =\left[\dot{Q}_{a g g, 1}, \dot{Q}_{a g g, 2}, \dot{Q}_{a g g, 3}, \ldots, \dot{Q}_{a g g, n_{c}}\right]^{T} \\
\dot{\mathbf{Q}}_{\mathbf{b}} & =\left[\dot{Q}_{b}\right]^{T} \\
\mathbf{T}_{\mathbf{b}} & =\left[T_{b}\right]^{T}
\end{aligned}
$$

where $A_{Q}, B_{Q}$ and $C_{Q}$ are the matrices of the linear state-space model, obtained by combining and rearranging Equations 9 and 11. $A_{Q}$ represents a 285 time linear transfer map of the space-discretized aggregated heat loads $\left(\dot{Q}_{a g g, 1}\right.$, $\left.\ldots, \dot{Q}_{a g g, n c}\right)$ in the load history, $B_{Q}$ is the heat gain matrix from the borehole heat flow $\left(\dot{Q}_{b}\right)$, while $C_{Q}$ represents the mapping of the aggregated heat loads to the borehole wall temperatures. The borehole and the ground models can be combined into one single SSM model: 


$$
\begin{aligned}
\frac{\partial \mathbf{x}}{\partial t} & =A(p) \quad \mathbf{x}+B \quad \mathbf{u} \\
\mathbf{y} & =C \quad \mathbf{x} \\
\mathbf{x} & =\left[\mathbf{T}^{T}, \dot{\mathbf{Q}}_{\mathbf{a g g}}^{T}\right]^{T} \\
\mathbf{u} & =\left[\dot{Q}_{f}\right]^{T} \\
\mathbf{y} & =\left[T_{f m}\right]^{T}
\end{aligned}
$$

The model dimensionality includes a large quantity of unmeasured states compared to its number of inputs and outputs and the number of available measurements.

\subsection{State estimation}

State estimators or state observers are used in models whose states are hidden, i.e. it is not possible to measure all system states. They provide an estimate of these internal states for a real system from measurements of the inputs and the outputs of the real system. Their main challenge is to solve a problem where the number of knowns (input and output measurements) is smaller than the number of unknowns (states). In the literature, there exist many state estimation methods. We restrict the scope of this work to the family of Bayesian estimators, which are recommended when: (i) full information about the system dynamic behavior is available and (ii) there exists uncertainty in some of the parameters of the system [31. Bayesian observers are algorithms based on probabilistic distributions of the process nois $\mathrm{L}^{2} S$ and measurement noise $R$. Since the borefield model is linear, we apply two linear state observers: Time-varying Kalman Filter (TVKF) and Moving Horizon Estimation (MHE).

\footnotetext{
${ }^{2}$ In the literature, the process noise matrix is commonly referred as $Q$. We use the notation $S$ to avoid confusion with the heat flow rates.
} 


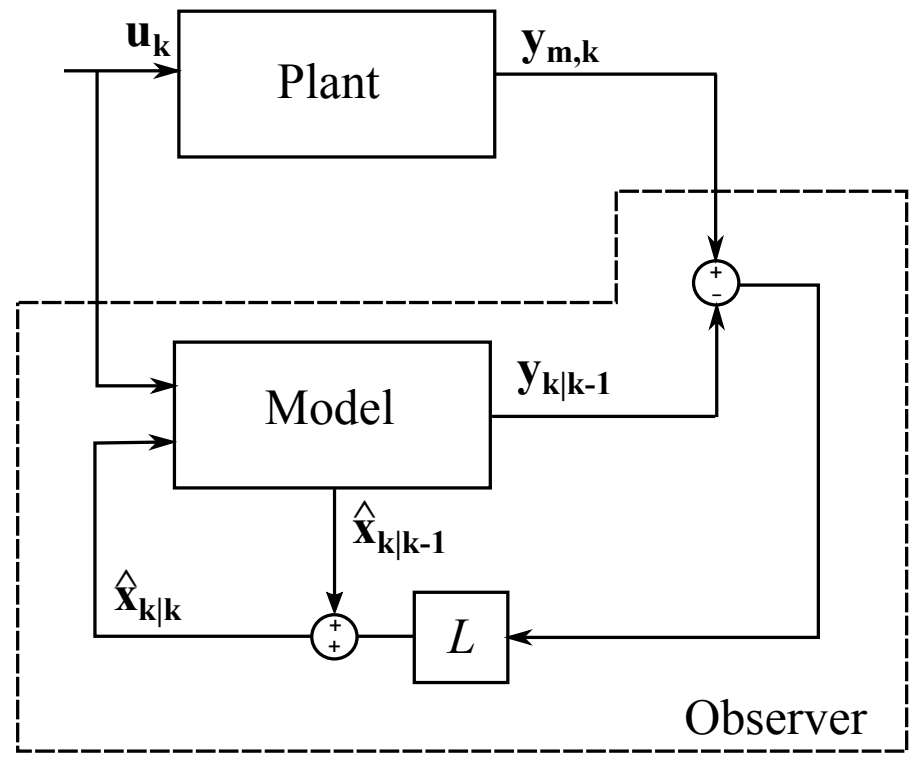

Figure 4: Kalman filter representation: The updated states $\hat{\mathbf{x}}_{\mathbf{k} \mid \mathbf{k}}$ are estimated using the predicted states $\hat{\mathbf{x}}_{\mathbf{k} \mid \mathbf{k}-\mathbf{1}}$ and the difference between the output $\mathbf{y}_{\mathbf{k} \mid \mathbf{k}-\mathbf{1}}$ (resulting from the states $\hat{\mathbf{x}}_{\mathbf{k} \mid \mathbf{k}-\mathbf{1}}$ ) and the measurements $\mathbf{y}_{\mathbf{m}, \mathbf{k}}$.

\subsubsection{Time-varying Kalman Filter}

The Kalman Filter (KF) is one of the most popular estimation techniques in the literature for many different engineering applications. KF is a simple and practical algorithm that relies on the SSM matrices, and with proper tuning it can achieve excellent performance [32. A representation of a $\mathrm{KF}$ is given in Figure 4 In essence, the KF algorithm can be considered as a discrete two-step feedback system with a proportional gain $L$. At each time-step $k$, an update step is made where the predicted states at time-step $k-1$ are updated using the information from the measurements:

$$
\begin{aligned}
\hat{\mathbf{x}}_{\mathbf{k} \mid \mathbf{k}} & =\hat{\mathbf{x}}_{\mathbf{k} \mid \mathbf{k}-\mathbf{1}}+L_{k}\left(\mathbf{y}_{\mathbf{m}, \mathbf{k}}-\mathbf{y}_{\mathbf{k} \mid \mathbf{k}-\mathbf{1}}\right) \\
& =\hat{\mathbf{x}}_{\mathbf{k} \mid \mathbf{k}-\mathbf{1}}+L_{k}\left(\mathbf{y}_{\mathbf{m}, \mathbf{k}}-C \hat{\mathbf{x}}_{\mathbf{k} \mid \mathbf{k}-\mathbf{1}}-D \mathbf{u}_{\mathbf{k}}\right)
\end{aligned}
$$


Then, a prediction step is made where the states at step $k+1$ are predicted using the physical model with the information at step $k$ :

$$
\hat{\mathbf{x}}_{\mathbf{k}+\mathbf{1} \mid \mathbf{k}}=A \hat{\mathbf{x}}_{\mathbf{k} \mid \mathbf{k}}+B \mathbf{u}_{\mathbf{k}}
$$

The Kalman gain $L$ can be computed a priori leading to a Stationary Kalman Filter (SKF), or it can be updated at each time-step extending to a TimeVarying Kalman Filter (TVKF). However, since the borefield model has a parameterized $A$ matrix there is no point in applying SKF. The Kalman gain $L$ for TVKF is given by:

$$
L_{k}=\frac{P_{k \mid k-1} C^{T}}{R_{k}+C P_{k \mid k-1} C^{T}}
$$

where $P$ is the error covariance matrix which is also defined by an updateprediction step via Equations $15 \mathrm{~d}$ and $15 \mathrm{e}$

$$
\begin{aligned}
& P_{k \mid k}=\left(I-L_{k} C\right) P_{k \mid k-1} \\
& P_{k+1 \mid k}=A P_{k \mid k} A^{T}+S_{k}
\end{aligned}
$$

where $I$ is the identity matrix.

\subsubsection{Moving Horizon Estimation}

Kalman Filters rely on the information they have from the previous timestep. To increase its accuracy, a constrained dynamic optimization problem can be formulated to reduce the process and measurement noise over the data window. However, it is clear that this full information (FI) estimation problem would grow up in time to a point where its computational burden would become intractable. Moving Horizon Estimation (MHE) is an approximation to this FI estimation. It considers a fixed horizon of previous measurements inside a moving time window that makes the problem feasible in practice. To account for the dropped measurements past the considered time window, an arrival cost term is introduced into the optimization problem [33. Moreover, constraints on the states and parameters of the model can be enforced as a method to improve the quality of the estimates. Figure 5 illustrates the MHE concept, which can be described by the following optimization problem: 

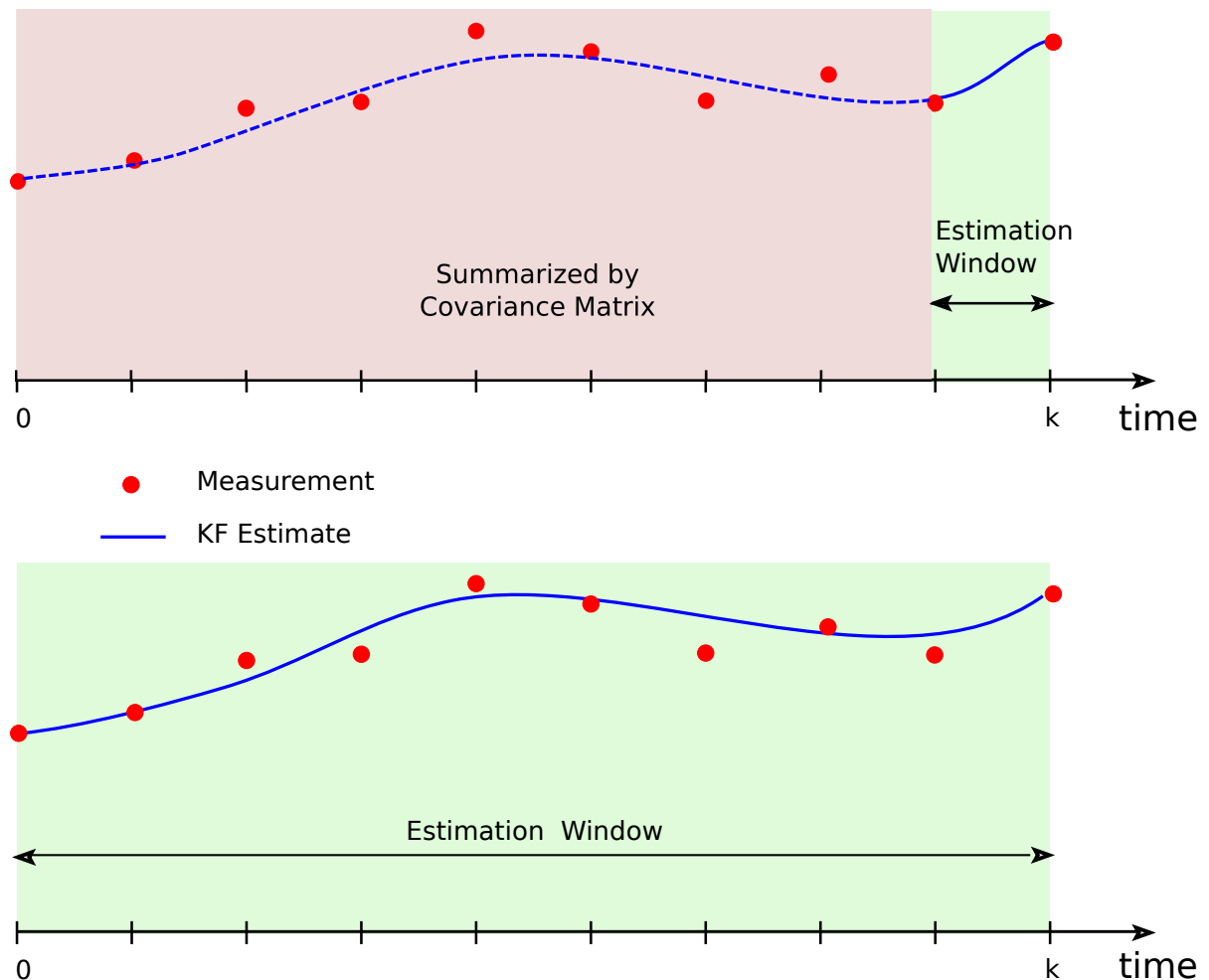

- Measurement

FI Estimate

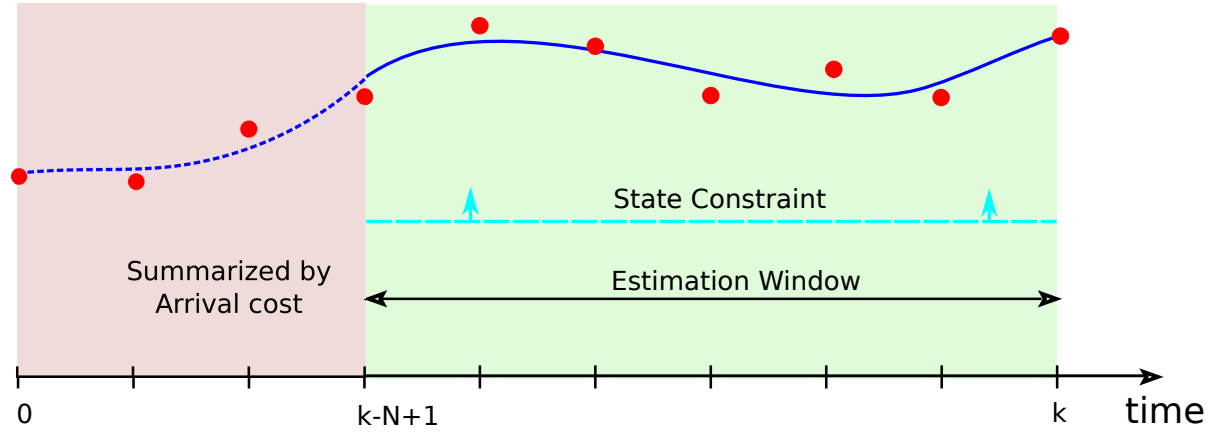

- Measurement

MHE Estimate

Figure 5: Comparison between Kalman Filter (KF), Full information (FI) estimation and Moving Horizon Estimation (MHE). 


$$
\begin{array}{cc}
\min _{\mathbf{x}_{\mathbf{k}-\mathbf{N}+\mathbf{1}}, W, V} & {\left[\|\Gamma\|_{P^{-1}}^{2}+\sum_{i=k-N+1}^{k-1}\left\|\mathbf{w}_{i}\right\|_{S^{-1}}^{2}+\sum_{i=k-N+1}^{k}\left\|\mathbf{v}_{i}\right\|_{R^{-1}}^{2}\right]} \\
\text { s.t. } \mathbf{x}_{\mathbf{i}+\mathbf{1}}=A \mathbf{x}_{\mathbf{i}}+B \mathbf{u}_{\mathbf{i}}+E \mathbf{d}_{\mathbf{i}}+\mathbf{w}_{\mathbf{i}}, & i \in N_{k-N+1}^{k-1} \\
\mathbf{y}_{\mathbf{i}}=C \mathbf{x}_{\mathbf{i}}+D \mathbf{u}_{\mathbf{i}}+\mathbf{v}_{\mathbf{i}}, & i \in N_{k-N+1}^{k} \\
\mathbf{x}_{\mathbf{i}} \in \mathcal{X}, \quad \mathbf{w}_{\mathbf{i}} \in \mathcal{W}, \quad \mathbf{v}_{\mathbf{i}} \in \mathcal{V} . & (16 \mathrm{~b})
\end{array}
$$

where $\mathbf{x}_{\mathbf{i}}, \mathbf{u}_{\mathbf{i}}, \mathbf{d}_{\mathbf{i}}, \mathbf{w}_{\mathbf{i}}$ and $\mathbf{v}_{\mathbf{i}}$ represent the vector of states, inputs, disturbances, process and measurement noise respectively, predicted at the $i$-th step of the estimation horizon $N$, and $W$ and $V$ are the concatenation of the vectors $\mathbf{w}_{\mathbf{i}}$ and $\mathbf{v}_{\mathbf{i}}$. Note that index $k$ denotes a current time sample, while index $i$ refers to the time index of the MHE. The predictions are obtained from the prediction model given by Eqs. $16 \mathrm{~b}$ and $16 \mathrm{c}$. Limits on state and noise variables are defined by eq. (16d). The term $\|a\|_{S}^{2}$ in the objective function represents the weighted squared 2-norm, i.e., $a^{T} S a$, with the weighting process, noise and error covariance matrices $S, R$, and $P$ given as positive definite diagonal matrices. The first term of the objective function $\Gamma$ stands for the so called arrival cost, which represents the summarized effect of data from previous time-steps outside the estimation window $N$.

\section{Virtual experiment set-up}

The methodology is applied to the borefield of a cooling-dominated office building located in Dilbeek, Brussels, Belgium. The building conditioned space is $2232 \mathrm{~m}^{2}$ and is equipped with a borefield of $37 \times 94 \mathrm{~m}$ deep double- $\mathrm{U}$ tubes, distributed around the building separated by an intermediate $6 m$ as shown by Figure 6 .

Further details on the borefield parameters can be found in Table 1. The thermal properties of the ground are extracted from the SmartGeotherm tool [34, 


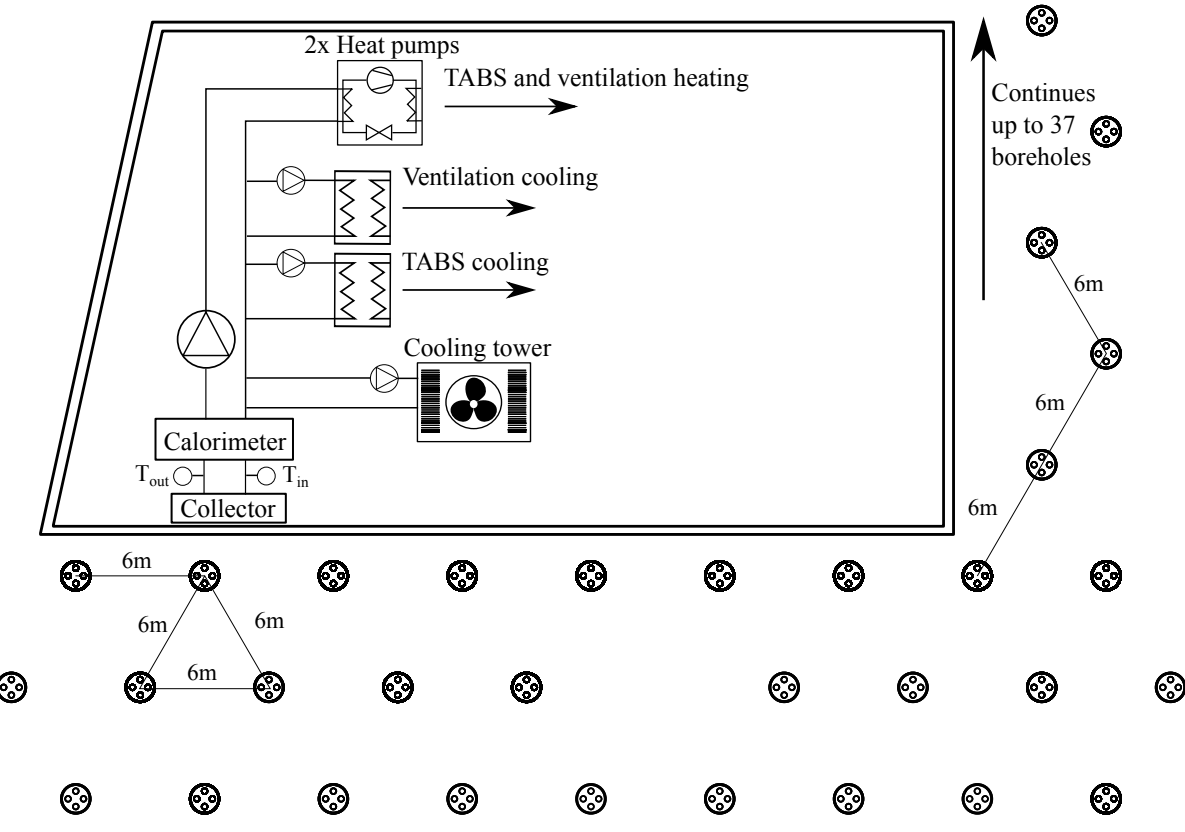

Figure 6: Distribution of the boreholes around the building envelope and hydronic schematic of the building (TABS stands for thermally activated building syste).

which provides information about the ground composition and the average ground thermal conductivity for any location in Flanders, since no thermalresponse-test (TRT) is available. The geothermal gradient is calculated using a geothermal heat flow of $0.07 \mathrm{~W} / \mathrm{m}^{2}$ as documented by Earth-Energy-Designer for the location of Brussels [35, which also indicates an undisturbed ground temperature $T_{s}$ of $9.7^{\circ} \mathrm{C}$. The resolution of the load aggregation scheme $\Delta t_{0}$ is set to $480 \mathrm{~s}$ (8 minutes), which corresponds to the resolution of the monitoring system. All the other parameters are extracted from the installation technical documentation. Two ground-source heat pumps of $70 \mathrm{~kW}$ nominal capacity each provide heating to the building, while direct cooling is supplied by means of two heat exchangers. A variable-speed hydraulic pump circulates a mixture of propylene glycol and water at $30 \%$ weight with a maximum volumetric flow rate of $38 \mathrm{~m}^{3} / \mathrm{h}$. Despite being a 10-year-old building, monitored data from the borefield is only available for 1.5 years, as the calorimeters were recently 
Table 1: Summary of the borefield parameters of the office building

\begin{tabular}{|c|c|c|c|c|c|c|c|}
\hline \multicolumn{4}{|c|}{ Borehole parameters } & \multicolumn{4}{|c|}{ Piping parameters } \\
\hline Notation & Description & Value & Units & Notation & Description & Value & Units \\
\hline$r_{b}$ & Borehole radius & 75.0 & $m m$ & $r_{p}$ & Pipe radius & 16.0 & $\mathrm{~mm}$ \\
\hline$H_{b}$ & Borehole height & 94.0 & $m$ & $k_{p}$ & Pipe conductivity & 0.42 & $W /(m . K)$ \\
\hline$d_{b}$ & Borehole burial depth & 1.0 & $m$ & $e_{p}$ & Pipe thickness & 3.0 & $m m$ \\
\hline$n_{b}$ & Number of boreholes & 37 & - & $x_{C}$ & Pipe spacing & 85.0 & $m m$ \\
\hline \multicolumn{4}{|c|}{ Ground parameters } & \multicolumn{4}{|c|}{ Grout parameters } \\
\hline Notation & Description & Value & Units & Notation & Description & Value & Units \\
\hline$k_{s}$ & Ground conductivity & 1.30 & $W /(m . K)$ & $k_{g}$ & Grout conductivity & 2.35 & $W /(m . K)$ \\
\hline$c_{s}$ & Ground heat capacity & 980 & $J /(k g . K)$ & $c_{g}$ & Grout heat capacity & 1550 & $J /(k g . K)$ \\
\hline$\rho_{s}$ & Ground density & 1358 & $\mathrm{~kg} / \mathrm{m}^{3}$ & $\rho_{g}$ & Grout density & 1225 & $\mathrm{~kg} / \mathrm{m}^{3}$ \\
\hline$T_{s}$ & Undisturbed ground temperature & 9.7 & ${ }^{\circ} \mathrm{C}$ & & & & \\
\hline$d T_{s} / d z$ & Geothermal gradient & 0.05 & ${ }^{\circ} \mathrm{C} / \mathrm{m}$ & & & & \\
\hline
\end{tabular}

365 borefield, the fluid flow rate and the fluid heat flow in intervals of 8 minutes. It has to be noted that the calorimeters are installed in the building cellar, causing the temperature sensors to converge to the cellar temperature when no flow is passing through. As we know beforehand that such data are not related to the phenomena investigated, it has been filtered out from the data-set.

Simulations are set up using the BeSim framework in Matlab [36, which is built upon the modeling and optimization toolbox YALMIP [37]. The optimization problem resulting from the MHE is solved using Gurobi [38]. Table 2 summarizes the simulation conditions applied in this research. The temperature the effects of the geothermal gradient. The load history for simulations 1a, 2a and $3 \mathrm{a}$ is initiated as if it was empty. Simulations $1 \mathrm{~b}$ and $2 \mathrm{~b}$ are initiated with an initial guess of aggregated loads which results from a previous simulation that applies a constant load for 10 years to minimize the error between the simulation mean fluid temperature and the measured one. The process, noise and covariance matrices are chosen based on a trial-and-error procedure extending from previous work [19]. Based on the results of the simulations, we decided not to run an extra simulation $3 \mathrm{~b}$ with the initial guesses of aggregated loads.

The simulations are run for 585 days of data starting at the end of February 
Table 2: Summary of the simulation conditions in the cases considered.

\begin{tabular}{|c|c|c|c|c|c|}
\hline \multirow{2}{*}{ Case } & \multirow{2}{*}{ Initial load states $\left(\mathbf{x}_{\mathbf{0}}\right)$} & Estimator & \multicolumn{3}{|c|}{ Estim. matrices } \\
\cline { 3 - 6 } & & $\mathrm{S}$ & $\mathrm{R}$ & $\mathrm{P}$ \\
\hline $1 \mathrm{a}$ & Empty & No estimator (Open-loop) & $\mathrm{N} / \mathrm{A}$ & $\mathrm{N} / \mathrm{A}$ & $\mathrm{N} / \mathrm{A}$ \\
\hline $1 \mathrm{~b}$ & Guess & No estimator (Open-loop) & $\mathrm{N} / \mathrm{A}$ & $\mathrm{N} / \mathrm{A}$ & $\mathrm{N} / \mathrm{A}$ \\
\hline $2 \mathrm{a}$ & Empty & TVKF & $1 \mathrm{e} 10$ & $1 \mathrm{e} 1$ & $1 \mathrm{e} 1$ \\
\hline $2 \mathrm{~b}$ & Guess & TVKF & $1 \mathrm{e} 10$ & $1 \mathrm{e} 1$ & $1 \mathrm{e} 1$ \\
\hline $3 \mathrm{a}$ & Empty & TVKF (Borehole model) & $1 \mathrm{e} 10$ & $1 \mathrm{e} 1$ & $1 \mathrm{e} 1$ \\
& & MHE (Ground model) & $1 \mathrm{e} 6$ & $1 \mathrm{e} 1$ & $1 \mathrm{e} 1$ \\
\hline
\end{tabular}

in time-steps of 8 minutes, in order to match with the time resolution of the calorimeters and comprising a total number of time-steps $N_{\text {sim }}=105300$. The model in Equation 14 is loaded into BeSim and converted from its continuous formulation to a discrete 8-minutes resolution formulation using the MATLAB embedded function c2d. At the start of each time-step $k$, the $A$ matrix of the borefield model is re-computed using the mass flow rate measurement from the calorimeter. In the open-loop simulations $1 \mathrm{a}$ and $1 \mathrm{~b}$, the output (i.e. the mean fluid temperature) at time-step $k$ and the predicted state vector at the time-step $k+1$ are calculated using Equations $14 \mathrm{a}$ and $14 \mathrm{~b}$. In simulations $2 \mathrm{a}$ and $2 \mathrm{~b}$, at each time-step, the need for pre-filtering the measurement data is checked first to assess whether the measured data is corrupted. If the data point is valid, TVKF is applied and the state vector is updated using Equations 15c and 15a to compute the new state prediction at $k+1$ (Equation $15 \mathrm{~b}$ ) and the estimated output. The error covariance matrix $P$ is also updated and then predicted by Equations $15 \mathrm{~d}$ and $15 \mathrm{e}$. If the data is filtered out, the corresponding time-step is simulated in open-loop using Equations 14 and $14 \mathrm{~b}$.

To reduce the complexity of the MHE optimization in simulation 3a, the estimator is only applied to the ground model, thus avoiding the implementation of the parameterized A matrix in the optimization formulation. This is justified since the long-term dynamics of the model are stored within the ground load states, while the short-term dynamics are stored within the temperature 
states. Hence, as in simulations $2 \mathrm{a}$ and $2 \mathrm{~b}$, TVKF is applied first to obtain an initial set of state estimates. Using the resulting estimates of the borehole wall temperature $T_{b}$ as the reference value and $\dot{Q}_{b}$ as the input value, MHE is then applied to the ground model with a window frame of 1 day $(N=180)$ to refine the estimates of the ground loads. The optimization to find the set of aggregated load estimates $\hat{\mathbf{Q}}_{\text {agg }}$ is therefore formulated at each time-step $k$ with the following constraints:

$$
\begin{aligned}
& \min _{\hat{\mathbf{Q}}_{\mathrm{agg} \mathbf{k}-\mathbf{N}+\mathbf{1}}, W, V} \sum_{i=k-N+1}^{k-1}\left\|\mathbf{w}_{\mathbf{i}}\right\|_{S^{-1}}^{2}+\sum_{i=k-N+1}^{k}\left\|\mathbf{v}_{\mathbf{i}}\right\|_{R^{-1}}^{2} \\
& \text { s.t. } \dot{\mathbf{Q}}_{\mathbf{a g g} i+1}=A_{Q} \dot{\mathbf{Q}}_{\mathbf{a g g} i}+B_{Q} \dot{\mathbf{Q}}_{\mathbf{b} i}+\mathbf{w}_{\mathbf{i}}, \quad i \in N_{k-N+1}^{k-1} \\
& \mathbf{T}_{\mathbf{b} i}=C_{Q} \dot{\mathbf{Q}}_{\mathbf{a g g} i}+\mathbf{v}_{\mathbf{i}}, \quad i \in N_{k-N+1}^{k} \\
& \hat{\dot{Q}}_{a g g, j, i}=\dot{Q}_{a g g j, i} \quad i \in N_{k-N+1}^{k} \\
& j \in 1,2 \ldots m \\
& \hat{Q}_{a c c, i} \geq 0 \\
& \hat{\dot{\mathbf{Q}}}_{\mathrm{agg}, \mathbf{i}} \in \mathcal{X}, \mathbf{w}_{\mathbf{i}} \in \mathcal{W}, \quad \mathbf{v}_{\mathbf{i}} \in \mathcal{V} \text {. }
\end{aligned}
$$

where $m$ represents the aggregation cell where the load history becomes unknown, and $\dot{Q}_{a g g, j, i}$ and $\hat{\dot{Q}}_{a g g, j, i}$ represent the predicted and estimated aggregated load in the j-th cell at the i-th MHE time-step. As the simulation problem advances in time, the point where the load history is unknown is further in the past and consequently the number of states to be guessed becomes smaller. This feature is enforced by constraint (17d): the first aggregation cells keep the value from the previous prediction step while the cells beyond the point $m$ until $n_{c}$ have a higher degree of freedom. Additionally, constraint $17 \mathrm{e}$ forces the ground load balance to be positive, in accordance to what is expected from a cooling-dominated building. Thus, no arrival cost $\Gamma$ is defined as the information from previous history is implicitly included within the formulated constraints. The MHE state, process and noise bounds (Equation 17f) are kept ${ }_{425}$ within $\pm 3 \mathrm{E} 5 \mathrm{~W}, \pm 1 \mathrm{E} 2 \mathrm{~W}$ and $\pm 1 \mathrm{E}-1 \mathrm{~K}$ respectively. The optimization vari- 
ables include: the estimated states $\dot{\mathbf{Q}}_{\text {agg }}$ over the horizon $N$, the estimated state update error $W$ and the estimated measurement error $V$. The first element of the optimized estimated states over the horizon $\hat{\mathbf{Q}}_{\mathbf{a g g k}-\mathbf{N}+\mathbf{1}}$ is selected and the current estimated states $\hat{\mathbf{Q}}_{\text {aggk }}$ are calculated by integration using $W$ via the 430 so-called state condensing method [39]. This technique can efficiently reduce the number of optimization variables and as such speed up the solver.

\section{Results and discussion}

The main objective of the estimators is to reduce the 1-step ahead output error between the estimated output and the real measurement $\mathbf{y}_{\mathbf{e}}=\hat{\mathbf{y}}-\mathbf{y}_{\mathbf{m}}$. However, the predictions of the fluid temperatures in the longer-term are also of interest. Section 4.1 elaborates on the results obtained from the estimators with a focus on 1-step predictions, while Section 4.2 evaluates the performance of the estimators in the longer run. Please note that the model output $y$ in this case is the mean fluid temperature $T_{f m}$.

\subsection{1-step ahead predictions}

The 1-step ahead output error results are evaluated towards the following key performance indicators (KPIs), summarized in Table 3

- the average absolute output error $\left(A A O E=\sum_{k=1}^{N_{s i m}}\left|\mathbf{y}_{\mathbf{e}, \mathbf{k}}\right| / N_{\text {sim }}\right)$,

- the absolute maximum output error $\left(\max \left|\mathbf{y}_{\mathbf{e}}\right|\right)$,

- the mean output error $\left(\overline{\mathbf{y}_{\mathbf{e}}}\right)$, and

- the average simulation time per time-step $\left(t_{\text {sim,step }}=t_{\text {sim }} / N_{\text {sim }}\right)$.

Figure 7 compares the box plots of the output errors $\mathbf{y}_{\mathbf{e}}$ for the different simulations cases (as listed in Table 2 for the full period of 585 days). The open-loop simulation (1a) clearly underpredicts the fluid temperature of the system, in accordance to our expectations from the load history of a coolingdominated building. Simulation $1 \mathrm{~b}$ shows that this effect can be mitigated by 
Table 3: 1-step ahead output numerics.

\begin{tabular}{|c|c|c|c|c|}
\hline Case & $A A O E[\mathbf{K}]$ & $\overline{\mathbf{y}_{\mathbf{e}}}[\mathbf{K}]$ & $\max \left|\mathbf{y}_{\mathbf{e}}\right|[\mathbf{K}]$ & $t_{\text {sim,step }}[\mathbf{s}]$ \\
\hline $1 \mathrm{a}$ & $2.50 E 0$ & $-2.50 E 0$ & $7.62 E 0$ & $1.34 E-2$ \\
\hline $1 \mathrm{~b}$ & $6.47 E-1$ & $-2.14 E-1$ & $5.69 E 0$ & $1.40 E-2$ \\
\hline $2 \mathrm{a}$ & $6.39 E-2$ & $-5.63 E-2$ & $8.71 E-1$ & $1.65 E-2$ \\
\hline $2 \mathrm{~b}$ & $3.47 E-2$ & $-7.90 E-3$ & $7.58 E-1$ & $1.71 E-2$ \\
\hline $3 \mathrm{a}$ & $2.59 E-2$ & $1.43 E-5$ & $6.38 E-1$ & $8.81 E-2$ \\
\hline
\end{tabular}

a reasonable guess of the annual load imbalance of the ground, by modifying Equation $8 \mathrm{~b}$ to include the annual load imbalance at all times from the start of system operation (which is taken at 10 years) until the start of the simulation:

$$
\dot{Q}_{a g g}(t=0, \tau)=\dot{Q}_{\text {annual }}, \tau<=10 \text { years }
$$

All three simulation cases with an estimator implemented (2a, 2b and $3 \mathrm{a})$ outperform the simulations without, with an output error typically an order of magnitude lower. A closer look at the output KPIs can be found in Table 3 . It is shown that, with a reasonable estimate of the previous history, TVKF performance can be increased. With the adequate selection of the constraints, MHE outperforms TVKF in terms of error defined KPIs regardless of the previous load history estimate. However, this performance increase comes at the cost of about 5 times more computation time per simulation step as MHE requires to solve an optimization problem.

To enable minimization of the 1-step ahead output error, the estimators have a direct effect on the temperature states of the model, i.e. borehole fluid, grout and wall temperatures, as their influence on the short-term dynamics is higher. Contrary to the output evaluation, there is no direct measurement of these states, consequently we analyze the temperature differences on the temperature states $\mathbf{x}_{\mathbf{d}}$ between open-loop simulations and applying TVKF. Note that only TVKF evaluation is done since simulation case 3a uses this state observer to estimate the temperature states. Analogously to the previous case, 


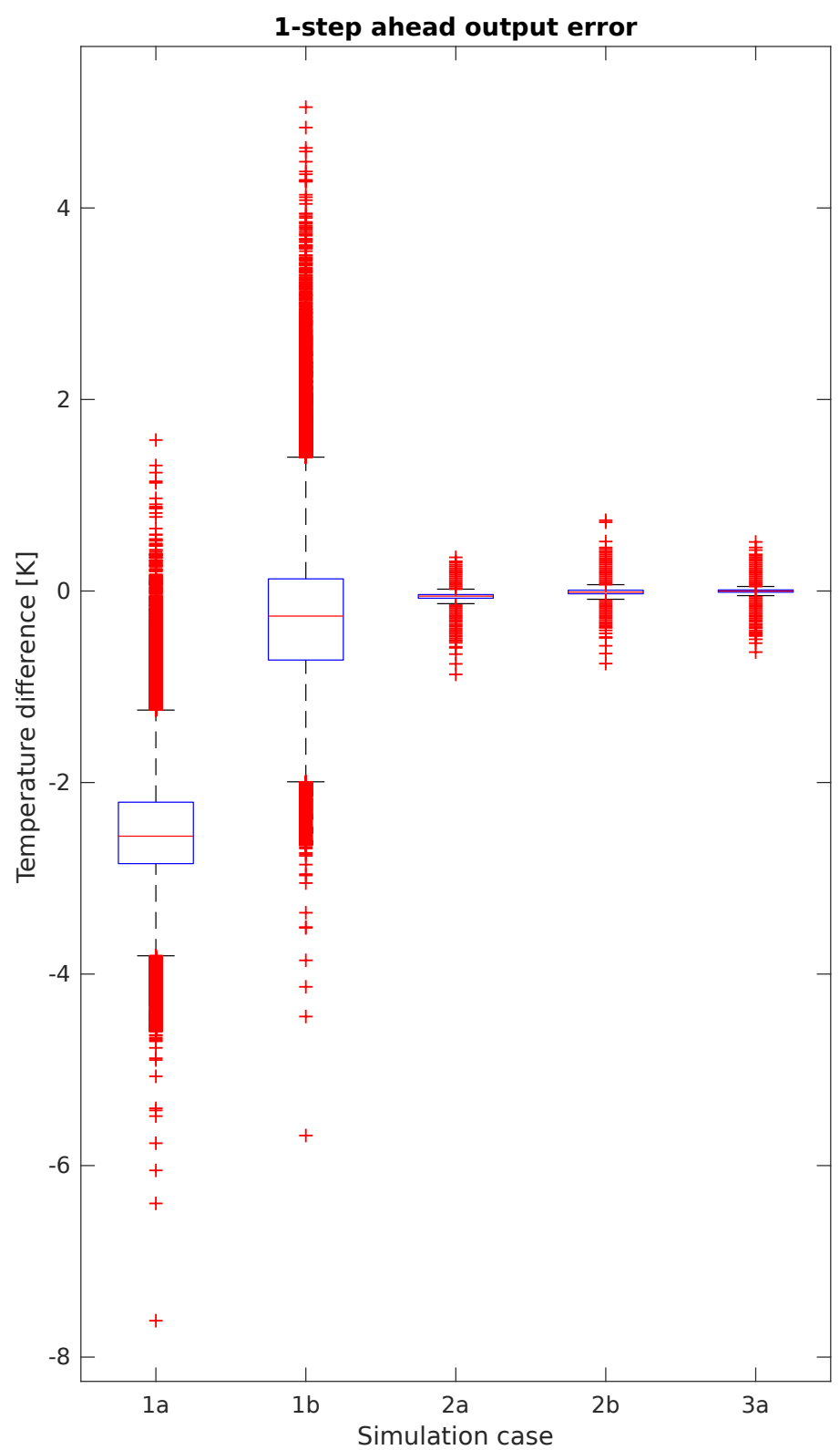

Figure 7: Box plots of the estimated output open-loop/estimation errors for the different experiments. 
Table 4: Temperature state difference numerics.

\begin{tabular}{|c|c|c|c|c|c|c|}
\hline \multirow{2}{*}{ State set } & \multicolumn{3}{|c|}{ Difference 1a-2a } & \multicolumn{3}{c|}{ Difference 1b-2b } \\
\cline { 2 - 7 } & $A A D[\mathbf{K}]$ & $\overline{\mathbf{x}_{\mathbf{d}}}[\mathbf{K}]$ & $\max \mathbf{x}_{\mathbf{d}}[\mathbf{K}]$ & $A A D[\mathbf{K}]$ & $\overline{\mathbf{x}_{\mathbf{d}}}[\mathbf{K}]$ & $\max \left|\mathbf{x}_{\mathbf{d}}\right|[\mathbf{K}]$ \\
\hline Fluid & $2.06 E 0$ & $-2.02 E 0$ & $1.28 E 1$ & $7.36 E-1$ & $1.45 E-1$ & $1.05 E 1$ \\
\hline Grout & $2.06 E 0$ & $-2.06 E 0$ & $4.34 E 0$ & $4.33 E-1$ & $-1.51 E-1$ & $3.72 E 0$ \\
\hline Wall & $2.00 E 0$ & $-2.00 E 0$ & $3.81 E 0$ & $4.11 E-1$ & $-1.43 E-1$ & $2.20 E 0$ \\
\hline Total & $2.12 E 0$ & $-2.12 E 0$ & $1.28 E 1$ & $4.63 E-1$ & $-1.60 E-1$ & $1.05 E 1$ \\
\hline
\end{tabular}

the evaluation is done based on the following KPIs, summarized in Table 4

- the average absolute temperature difference $\left(A A D=\sum_{k=1}^{N_{s i m}}\left|\mathbf{x}_{\mathbf{d}, \mathbf{k}}\right| /\left(n_{x} N_{s i m}\right)\right)$,

- the absolute maximum temperature difference $\left(\max \left|\mathbf{x}_{\mathbf{d}}\right|\right)$, and

- the mean temperature difference $\left(\overline{\mathbf{x}_{\mathbf{d}}}\right)$ for each set of fluid, grout and wall temperatures $n_{x}$.

On average, TVKF needs to correct about $2.1^{\circ} \mathrm{C}$ when the model is initiated with an empty load history and $0.5^{\circ} \mathrm{C}$ if an estimate of the load history is first provided, pointing again towards a cooling-dominated building. As expected, these differences are higher the faster the dynamics of the states are. The fluid temperatures have the fastest dynamics, and the wall temperatures the slowest. Since the aggregated load states travel in time, the same analysis is not repeated for that set of states.

Figure 8 shows the accumulated load in the ground (given by Equation 12 ) over the simulation time. When the model is initiated without load history, it is observed from the open-loop simulations that despite being a cooling-dominated building, over the considered period the ground experienced a negative balance, more typical for heating-dominated buildings. Applying TVKF slowly corrects the negative imbalance towards a positive one to reduce the 1-step ahead output error. This correction effect is no longer needed when the states initial guess is more accurate, as it can be observed from the trajectories in experiments $1 \mathrm{~b}$ and 2b. On the other hand, despite being initiated without load history, the MHE accumulated load immediately jumps to a different order of magnitude thanks 


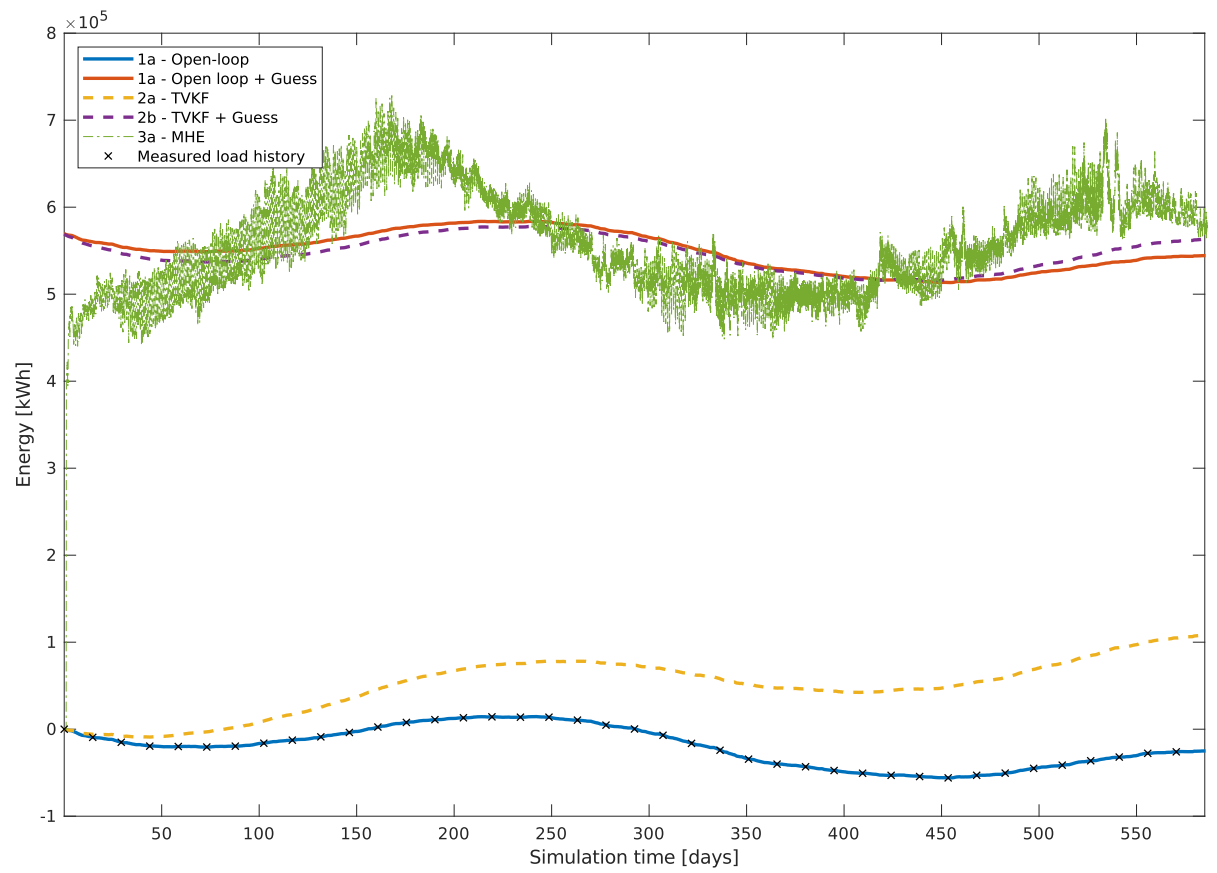

Figure 8: Accumulated ground load over the operation period shown during the simulation period.

to the constraints formulated in the optimization. The observed oscillations can be explained due to the high degree of freedom that the load states have from the point where the load history becomes unknown. Moreover, as the loads far away in time have a lower impact on the wall temperatures, to obtain a small change in the fluid temperature it is necessary a big change in the loads far in the past. A constraint on the accumulated load rate of change could be added to limit this effect and have a smoother load, however by doing so we found that this led to infeasible computational times.

The load correction effect seen in TVKF has a larger effect in the first load states, as it can be pointed out from Figure 9. The fluid load is represented from the steady-state time which is the characteristic time of the boreholes $\left(t_{b}=5 r_{b}^{2} / \alpha_{s}\right)$ until the end of the simulation period. In the long-term, the fluid and ground energy should be almost coincidental, however this is not the 
case when TVKF is being applied. This effect can be explained by looking at Equation 15a where all load and temperature states are updated proportionally to the computed Kalman Gain $L_{k}$. Comparing simulation cases 1a and 2a, the cells that are empty, i.e. the load history before the simulation, are barely affected. Even by introducing a load history as in simulation case $2 \mathrm{~b}$, the variation of the first cells that affect the immediate load history has a larger cumulative effect in time, producing the load mismatch between ground and fluid within the 585 days simulation period. An additional reason that causes the mismatch is associated with the update of the temperature states. By doing so, energy from the soil which was not registered through the fluid energy balance is being introduced/removed. This inherent feature of TVKF does not occur in MHE, where due to the constraints applied the load history during the simulation period is not affected, focusing more on finding a combination of the unknown aggregation cells that minimizes the borehole wall temperature error.

\section{2. $n$-step ahead predictions}

To analyze the performance of the estimators when there is a gap in the data or towards optimal control applications, we analyse the accuracy of openloop simulations after initialization of the model through varying periods of closed-loop simulations. Closed-loop simulations are run for cases 2a, $2 \mathrm{~b}$ and 3a. After each month of simulation, an open-loop simulation is started using the estimated states of the closed-loop simulations and the measured loads, and the obtained fluid predictions over time horizons of 1 hour, 6 hours, 24 hours, 3 days, 1 week and 1 month are compared to the monitored data. Figure 10 530 shows the values of $A A O E, \max \mathbf{y}_{\mathbf{e}}$, and $\overline{\mathbf{y}_{\mathbf{e}}}$ for the simulation periods of 1 hour, 6 hours, 24 hours, 3 days, 1 week and 1 month, starting after different periods of estimates. In general, and in line with our expectations, the errors increase with the considered simulation period for all the considered estimators. For a simulation time of 24 hours, the TVKF output error can average more than 1 ${ }^{\circ} \mathrm{C}$ if no estimate of the previous load history is provided beforehand, slowly returning to the underestimation of $2{ }^{\circ} \mathrm{C}$ given by the open-loop simulation 1a. 

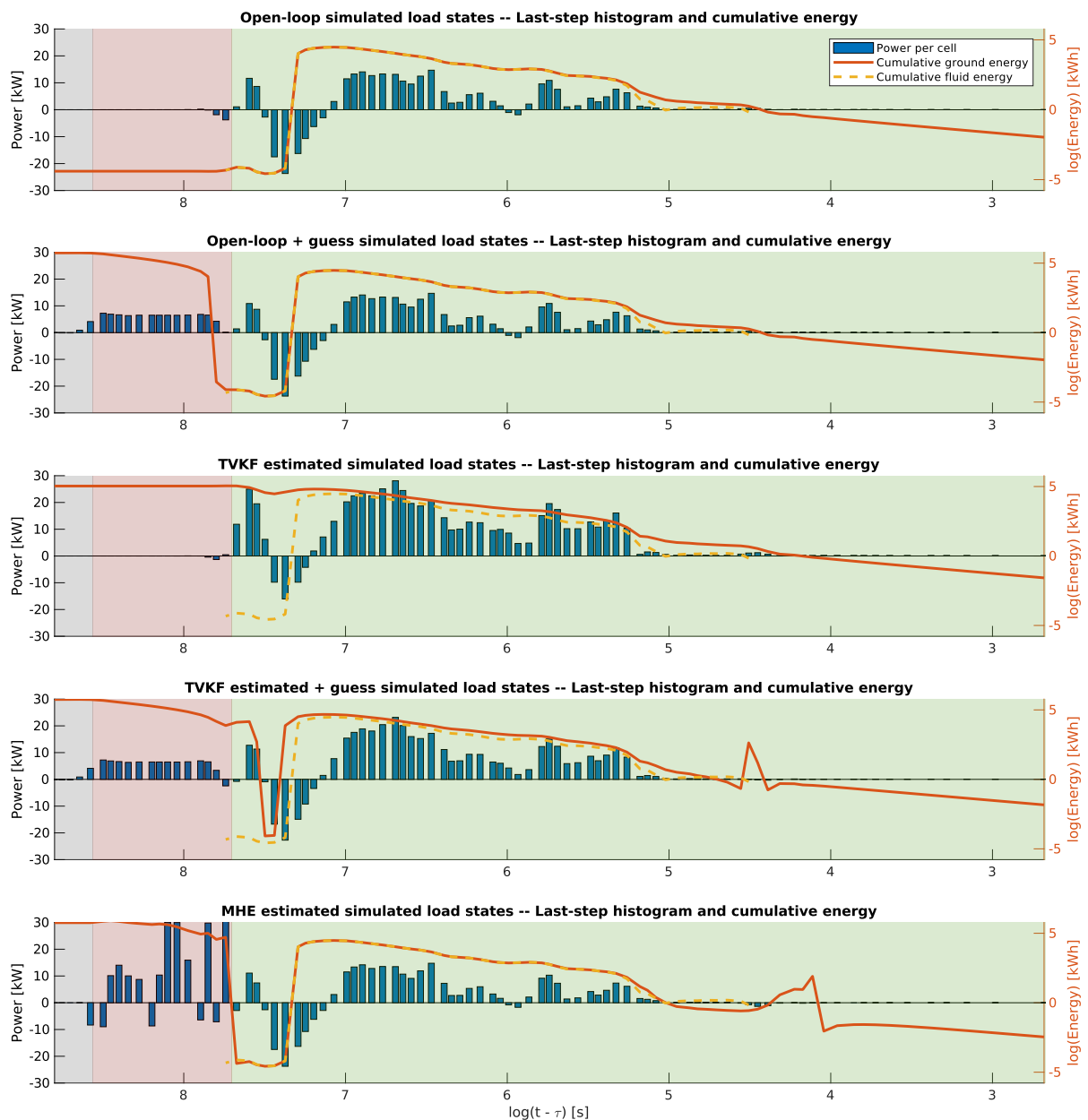

Figure 9: Histogram of aggregated loads and cumulative ground and fluid load at the end of the simulation. The fluid load is represented from $t_{b}$ till the end of the simulation period. Each bar represents the aggregated load state within the corresponding cell, positioned relatively to the current instant (cells on the right side are closer to the present). The green region corresponds to the simulation period (585 days). The red region corresponds to the building operation period (10 years). The grey period comprises the remaining cells until $\tau_{n_{c}}$ 

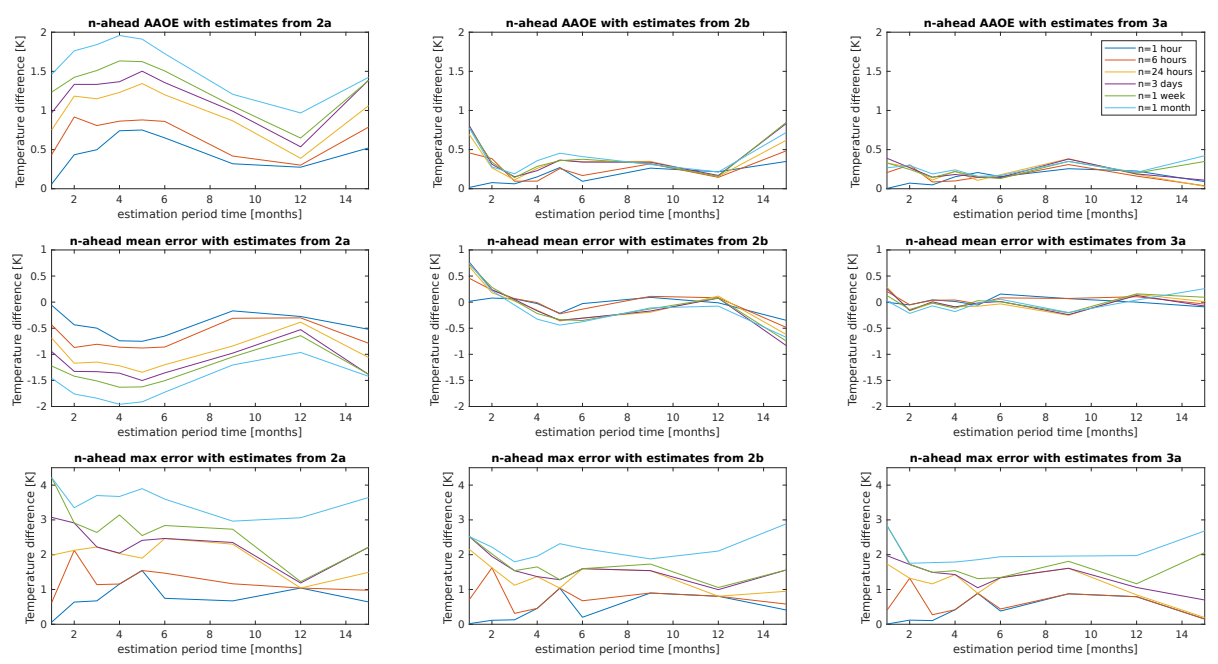

Figure 10: n-step ahead output KPIs after a period of estimates given by the x-axis for the different estimation experiments $2 \mathrm{a}, 2 \mathrm{~b}$ and $3 \mathrm{a}$.

The same trend is seen when the estimation of the previous load is provided, with TVKF returning to the underestimates of $0.5^{\circ} \mathrm{C}$ given by the open-loop simulation 1b. In these cases, we do not recommend TVKF for n-step output predictions longer than 6-24 hours. On the other hand, MHE is able to keep the average errors under $0.5^{\circ} \mathrm{C}$ even after long periods of time of 1 month and without previous initial estimate of loads provided. The length of the estimation period does not seem to have a clear effect on reducing the output errors, but depending on the time frame the open-loop simulation starts the error can be higher or lower. Based on the open-loop simulations with estimates from the estimation $2 \mathrm{a}$, we believe that this feature is related to the seasonality of the loads. The higher errors occur around month 5 which corresponds to the end of the cooling season, increasing the effect of the previous load history. On the other hand, lower errors occur at the end of the heating season where the surrounding ground is colder, compensating for the effect of the previous load history.

The best performance estimator (MHE, experiment 3a) is selected and compared against the open-loop simulation with an initial guess of the load history 
to evaluate the increase in performance. After each month of simulation, the 

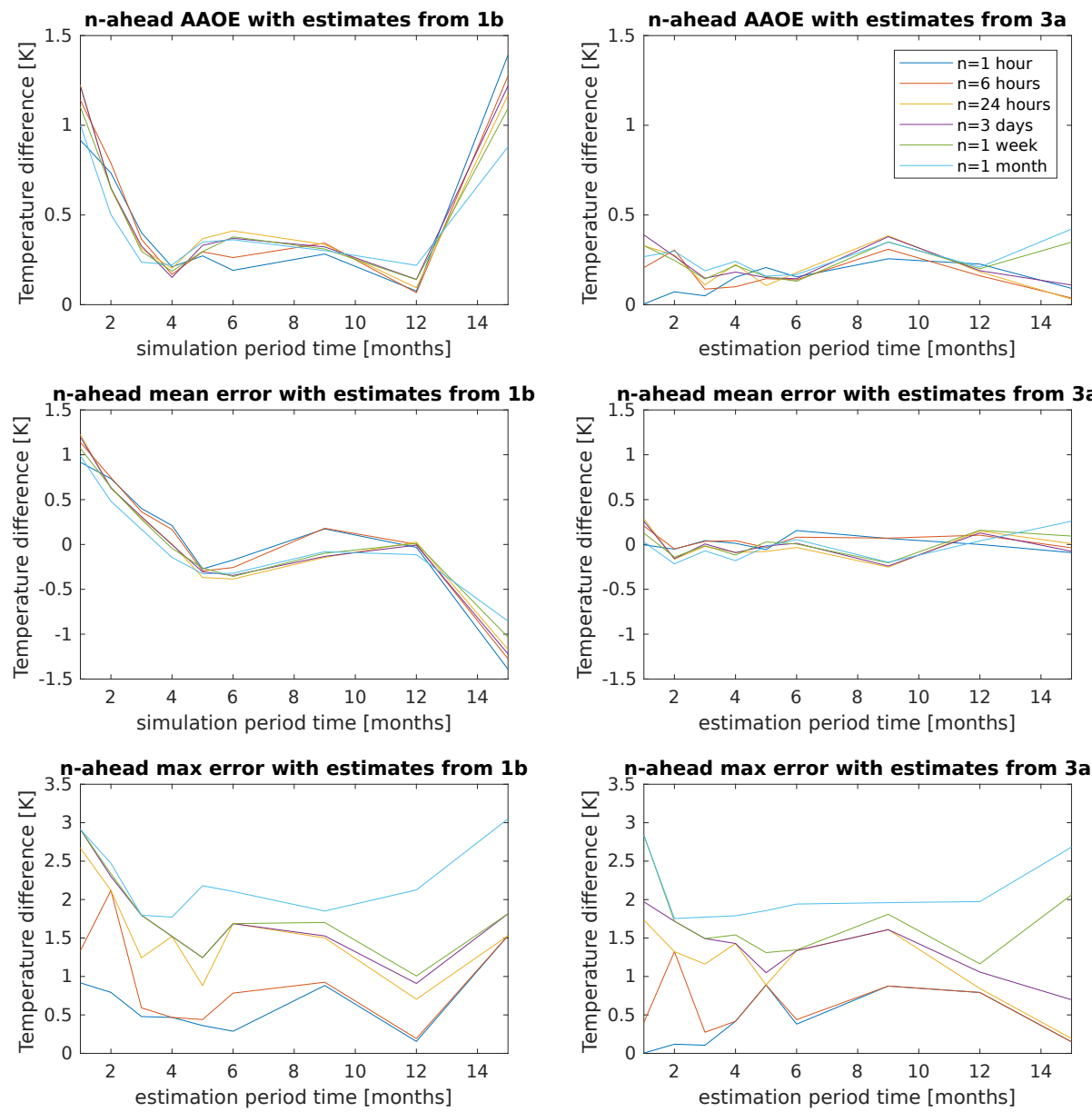

Figure 11: n-step ahead output KPIs after a period of simulation/estimates given by the $\mathrm{x}$-axis for the experiments $1 \mathrm{~b}$ (load history initial guess) and 3a (MHE). 
Both observers provide excellent results in predicting the borefield fluid temperature, with average and maximum 1-step ahead errors below $0.1{ }^{\circ} \mathrm{C}$ and 1 ${ }^{\circ} \mathrm{C}$ respectively when compared to the real measurement data, in contrast to the average and maximum errors of $2.5^{\circ} \mathrm{C}$ and $7.62{ }^{\circ} \mathrm{C}$ respectively of the open-loop simulation. To minimize this error, the estimators have a direct influence on the temperature states of the model, which contain the fast-dynamics information, and consequently the load is modified. This, however, comes with a mismatch between the cumulative ground and fluid loads in the known load history in the case of TVKF, independently of whether a previous unknown load history guess is provided or not. This feature can be corrected with the aid of constraints in the MHE formulation, therefore having a more realistic full load history profile over time. When assessing the open-loop n-step output errors after a period of estimates, it is observed that the error converges to the values of the full open-loop simulations for TVKF the further away the prediction is. The period of estimates does not seem to have a clear effect on the error reduction, but the time-frame where the open-loop simulations start does. MHE excels in keeping the output errors under $0.5{ }^{\circ} \mathrm{C}$ even after one month of open-loop simulation time and without a previous guess of the unknown load. The drawback of MHE is its increased computational burden, about 5 times higher than TVKF per time-step.

A raw estimation of the borefield load history which does not need to match the actual complete history can already get sufficiently accurate fluid tempera605 ture predictions. However, the estimators are able to get better fluid predictions in the short and long term compared to the case where the past load history is manually estimated, and they converge even by providing an initial inaccurate load estimate.

Future work can be directed towards the different individual aspects of the approach. The proposed discretized SSM model could be evaluated for different sampling times, different from the data acquisition resolution. The work on TVKF should be aimed at decoupling the Kalman Gain between the borehole and the ground model. Concerning the MHE, further tuning of the MHE 
optimization problem parameters and its formulation can be explored. For instance, different MHE estimation windows can be evaluated and compared to a full information optimization problem that takes into account the whole data set. The MHE accumulated load oscillations could be filtered out by introducing a constraint on the accumulated load variation or post-processing the resulting accumulated load by using a time-average approach. Finally, the application of the state observers to an optimal control problem or a case where exist unaccounted neighbouring ground source heat pump systems that affect the load history could be explored.

\section{Disclosure statement}

No potential conflict of interest was reported by the authors.

\section{${ }_{625}$ Acknowledgements}

The authors would like to acknowledge the funding of their research work by the EU within the H2020-EE-2016-RIA-IA programme for the project 'Model Predictive Control and Innovative System Integration of GEOTABS;-) in Hybrid Low Grade Thermal Energy Systems - Hybrid MPC GEOTABS' [grant number 723649 - MPC-; GT]. Furthermore, the InnoEnergy PhD School Programme and the European Institute of Technology (EIT) are acknowledged for supporting the international mobility from which this work was emerged.

This work emerged from the IBPSA Project 1, an international project conducted under the umbrella of the International Building Performance Simulation Association (IBPSA). Project 1 will develop and demonstrate a BIM/GIS and Modelica Framework for building and community energy system design and operation.

\section{Declarations of interest}

None. 


\section{References}

[1] S. Javed, J. Spitler, Accuracy of borehole thermal resistance calculation methods for grouted single U-tube ground heat exchangers, Applied Energy 187 (2017) 790 - 806. doi:https://doi.org/10.1016/j.apenergy. 2016. 11.079

${ }_{645}$ [2] J. Claesson, G. Hellström, Multipole method to calculate borehole thermal resistances in a borehole heat exchanger, HVAC\&R Research 17 (6) (2011) 895-911.

[3] L. Lamarche, S. Kajl, B. Beauchamp, A review of methods to evaluate borehole thermal resistances in geothermal heat-pump systems, Geothermics 39 (2) (2010) 187 - 200. doi:https://doi.org/10.1016/j.geothermics. 2010.03 .003

[4] A. S. Shirazi, M. Bernier, Thermal capacity effects in borehole ground heat exchangers, Energy and Buildings 67 (2013) 352 - 364. doi:https: //doi.org/10.1016/j.enbuild.2013.08.023

[5] D. Bauer, W. Heidemann, H. Müller-Steinhagen, H.-J. Diersch, Thermal resistance and capacity models for borehole heat exchangers, International Journal of Energy Research 35 (4) (2011) 312-320. doi:10.1002/er.1689.

[6] A. Zarrella, M. Scarpa, M. D. Carli, Short time step analysis of vertical ground-coupled heat exchangers: The approach of carm, Renewable Energy 36 (9) (2011) 2357 - 2367. doi:https://doi.org/10.1016/j.renene. 2011.01 .032

[7] P. Pasquier, D. Marcotte, Joint use of quasi-3D response model and spectral method to simulate borehole heat exchanger, Geothermics 51 (2014) 281 299. doi:https://doi.org/10.1016/j.geothermics.2014.02.001.

[8] D. Bauer, W. Heidemann, H.-J. Diersch, Transient 3D analysis of borehole heat exchanger modeling, Geothermics 40 (4) (2011) 250 - 260. doi:https: //doi.org/10.1016/j.geothermics.2011.08.001 
[9] P. Eskilson, Thermal analysis of heat extraction boreholes Ph.D (Doctoral dissertation, Thesis). Department of Mathematical Physics, University of Lund Lund, Sweden (1987).

[10] L. Ingersoll, H. Plass, Theory of the ground pipe source for the heat pump, ASHRAE Transactions 54 (1948) 339-348.

[11] H. S. Carslaw, J. C. Jaeger, Conduction of heat in solids, Oxford: Clarendon Press, 1959, 2nd ed.

[12] J. Claesson, P. Eskilson, Conductive heat extraction to a deep borehole: Thermal analyses and dimensioning rules, Energy 13 (6) (1988) 509-527.

[13] M. S. Mitchell, J. D. Spitler, Characterization, testing, and optimization

n. of load aggregation methods for ground heat exchanger response-factor models, Science and Technology for the Built Environment 25 (8) (2019) 1036-1051. arXiv:https://doi.org/10.1080/23744731.2019.1648936 doi:10.1080/23744731.2019.1648936. URL https://doi.org/10.1080/23744731.2019.1648936

[14] M. A. Bernier, P. Pinel, R. Labib, R. Paillot, A multiple load aggregation algorithm for annual hourly simulations of gchp systems, HVAC\&R Research 10 (4) (2004) 471-487.

[15] J. Claesson, S. Javed, A load-aggregation method to calculate extraction temperatures of borehole heat exchangers, ASHRAE Transactions 118 (1) (2012) 530-539.

[16] C. Verhelst, L. Helsen, Low-order state space models for borehole heat exchangers, HVAC\&R Research 17 (2011) 928-947. doi:10.1080/10789669. 2011.617188

[17] H. J. Witte, A. Cazorla-Marín, J. M. Corberán, An efficient borehole heat exchanger model for the analysis of transient thermal response: comparison with some existing models, in: Proceedings of EnerSTOCK 2018, Adana (Turkey), 25-28 April 2018. 
[18] I. Cupeiro Figueroa, D. Picard, L. Helsen, Short-term modeling of hybrid geothermal systems for model predictive control, Energy and Buildings 25 (8) (2019) 1095-1110. doi:10.1080/23744731.2019.1620564.

[19] I. Cupeiro Figueroa, J. Drgoňa, L. Helsen, State estimators applied to a linear white-box geothermal borefield controller model, in: Proceedings of International Building Simulation Conference 2019, 2019, Rome (Italy), 3-5 September 2019.

[20] F. De Ridder, M. Diehl, G. Mulder, J. Desmedt, J. Van Bael, An optimal control algorithm for borehole thermal energy storage systems, Energy and Buildings 43 (10) (2011) 2918 - 2925. doi:10.1016/j.enbuild.2011.07. 015 .

[21] E. Atam, D. O. Schulte, A. Arteconi, I. Sass, L. Helsen, Control-oriented modeling of geothermal borefield thermal dynamics through HammersteinWiener models, Renewable Energy 120 (2018) 468-477. doi:10.1016/j. renene.2017.12.105

[22] A. Laferrière, M. Cimmino, Model predictive control applied to residential self-assisted ground source heat pumps, in: Proceedings of International Ground Source Heat Pump Association Research Track, 2018, Stockholm (Sweden), 18-20 September 2018.

[23] A. Laferrière, M. Cimmino, Linear model predictive control for the reduction of auxiliary electric heating in residential self-assisted ground-source heat pump systems, Science and Technology for the Built Environment 25 (8) (2019) 1095-1110. doi:10.1080/23744731.2019.1620564.

[24] A. R. Puttige, S. Andersson, R. Östin, T. Olofsson, Improvement of bore720 hole heat exchanger model performance by calibration using measured data, Journal of Building Performance Simulation 13 (4) (2020) 430-

1442. arXiv:https://doi.org/10.1080/19401493.2020.1761451, doi: $10.1080 / 19401493.2020 .1761451$. URL https : //doi .org/10.1080/19401493.2020.1761451 
[31] J. M. Ali, N. H. Hoang, M. A. Hussain, D. Dochain, Review and classifica-

[25] M. L. Fasci, A. Lazzarotto, J. Acuña, J. Claesson, Analysis of the thermal interference between ground source heat pump systems in dense neighborhoods, Science and Technology for the Built Environment 25 (8) (2019) 1069-1080. doi:10.1080/23744731.2019.1648130

[26] I. Cupeiro Figueroa, J. Drgoňa, M. Abdollahpouri, D. Picard, L. Helsen, State observer for optimal control using white-box building models, in: Proceedings of Purdue Herrick Conferences, 2018, West Lafayette (USA), 9-12 July 2018.

[27] A. Laferrière, M. Cimmino, D. Picard, L. Helsen, Development and validation of a full-time-scale semi-analytical model for the short- and long-term simulation of vertical geothermal bore fields, Geothermics 86 (2020) 101788. doi:https://doi.org/10.1016/j.geothermics.2019.101788.

[28] M. Cimmino, M. Bernier, A semi-analytical method to generate gfunctions for geothermal bore fields, International Journal of Heat and n Mass Transfer 70 (2014) 641 - 650. doi:https://doi.org/10.1016/j. ijheatmasstransfer.2013.11.037.

[29] M. Cimmino, Fast calculation of the g-functions of geothermal borehole fields using similarities in the evaluation of the finite line source solution, Journal of Building Performance Simulation 11 (6) (2018) 655-668. doi: 10.1080/19401493.2017.1423390.

[30] B. Leonard, A stable and accurate convective modelling procedure based on quadratic upstream interpolation, Computer Methods in Applied Mechanics and Engineering 19 (1) (1979) 59 - 98. doi:https://doi.org/10. 1016/0045-7825(79)90034-3. tion of recent observers applied in chemical process systems, Computers \& Chemical Engineering 76 (2015) 27-41. 
[32] C. V. Rao, J. B. Rawlings, D. Q. Mayne, Constrained state estimation for nonlinear discrete-time systems: Stability and moving horizon approximations, IEEE transactions on automatic control 48 (2) (2003) 246-258.

[33] P. Kühl, M. Diehl, T. Kraus, J. P. Schlöder, H. G. Bock, A real-time algorithm for moving horizon state and parameter estimation, Computers \& chemical engineering 35 (1) (2011) 71-83.

[34] Geotermische Screeningstool - SmartGeotherm, http://tool. smartgeotherm.be/geo/alg, accessed: 2018-09-06.

[35] G. Hellström, B. Sanner, Earth energy designer, User's Manual, version 2 (2000).

[36] J. Drgoňa, BeSim Toolbox: Fast Development, and Simulation of Advanced Building Control, https://github.com/drgona/BeSim (2019).

[37] J. Löfberg, YALMIP: a toolbox for modeling and optimization in MATLAB Proc, in: CACSD Conf.(Taipei)(http://control. ee. ethz. ch./joloef/yalmip. php), 2004.

[38] G. Optimization, Inc., "Gurobi optimizer reference manual," 2015 (2015).

[39] G. Frison, J. Jorgensen, A fast condensing method for solution of linearquadratic control problems, in: Proceedings of 52nd IEEE Conference on Decision and Control, 2013, pp. 7715-7720. 